\title{
Fine-Tuning an Auditory Synapse for Speed and Fidelity: Developmental Changes in Presynaptic Waveform, EPSC Kinetics, and Synaptic Plasticity
}

\author{
Holger Taschenberger and Henrique von Gersdorff \\ The Vollum Institute, Oregon Health Sciences University, Portland, Oregon 97201
}

\begin{abstract}
Fast, precise, and sustained synaptic transmission at high frequency is thought to be crucial for the task of sound localization in the auditory brainstem. However, recordings from the calyx of Held synapse have revealed severe frequency-dependent synaptic depression, which tends to degrade the exact timing of postsynaptic spikes. Here we investigate the functional changes occurring throughout the critical period of synapse refinement from immature calyx terminal [postnatal day 5 (P5)] to after the onset of hearing (P12-P14). Surprisingly, for recordings near physiological temperature $\left(35^{\circ} \mathrm{C}\right)$, we find that $\mathrm{P} 14$ synapses are already able to follow extremely high input rates of up to $800 \mathrm{~Hz}$. This ability stems in part from a remarkable shortening of presynaptic action potentials, which may lead to a lowering of release probability and decrease in synaptic delays during development. In addition, AMPA receptor-mediated EPSCs as well as quantal synaptic currents acquired progressively faster kinet-
\end{abstract}

ics, although their mean amplitudes did not change significantly. NMDA receptor-mediated EPSCs, however, diminished with age, as indicated by a $50 \%$ reduction in mean amplitude and faster decay kinetics. Finally, the degree of synaptic depression was greatly attenuated with age, presumably because of a 2.5-fold or larger increase in the releasable pool of vesicles, which together with a decreasing release probability produces a fairly constant EPSC amplitude. This finely tuned orchestra of developmental changes thus simultaneously promotes speed while preventing premature vesicle pool depletion during prolonged bouts of firing. A few critical days in postnatal development can thus have a large impact on synaptic function.

Key words: development; MNTB; calyx of Held; AMPA and NMDA EPSCs; quantal and mEPSCs; short-term synaptic depression; patch-clamp; neuronal reliability
Auditory brainstem circuits can express unusually thick axons and giant, axo-somatic presynaptic terminals with multiple active zones. The calyx of Held synapse in the medial nucleus of the trapezoid body (MNTB) is a pivotal relay station that is involved in sound localization (Guinan and Li, 1990; Oertel, 1999). The binaural cue used is the difference in sound intensity received by the two cochleas. Contralateral inhibitory input via the MNTB and excitatory input from the ipsilateral cochlear nucleus are received by neurons in the lateral superior olive, where the two signals are first integrated (Sanes, 1990; Park et al., 1997). It is thought that microsecond differences in the arrival of action potentials (APs) are then used to pinpoint the locus of high-frequency sounds. Accordingly, in vivo (Rhode and Smith, 1986; Spirou et al., 1990) and brain slice recordings (Oertel, 1983; Banks and Smith, 1992) have established that the adult calyx of Held receives and follows high-input frequencies (e.g., $667 \mathrm{~Hz}$ at $34^{\circ} \mathrm{C}$; Wu and Kelly, 1993). Young rats [postnatal day 8 (P8)-P11], however, can only follow discharge rates up to $200 \mathrm{~Hz}$ (Borst et al., 1995; Brew and Forsythe, 1995). Several studies at end-bulb (Wu and Oertel, 1987; Zhang and Trussell, 1994a; Bellingham and Walmsley, 1999) and calyceal synapses (Forsythe et al., 1998; Wang and Kaczmarek, 1998) have also shown severe synaptic depression during stimulus trains. The reduced EPSP size will then degrade postsynaptic AP timing (Reyes et al., 1996).

Recent patch-clamp recordings have concentrated mostly on juvenile rats from P8 to P11 (Forsythe, 1994; Borst et al., 1995; Chuhma and Ohmori, 1998). However, the onset of hearing in rats

Received Aug. 23, 2000; revised Oct. 2, 2000; accepted Oct. 6, 2000.

This work was supported by a Pew Biomedical Research Scholar Award, an Alfred P. Sloan Neuroscience Scholar Award, and a National Institutes of Health RO1 grant. H.T. was supported by the Human Frontier Science Program. We thank Drs. C. E. Jahr and G. D. Pollack for valuable discussions and Drs. J. G. G. Borst, E. McCleskey, and L. Trussell for helpful comments on this manuscript.

Correspondence should be addressed to Henrique von Gersdorff, The Vollum Institute, Oregon Health Sciences University, 3181 SW Sam Jackson Park Road, Portland, OR 97201. E-mail: vongersd@ohsu.edu.

Copyright (C) 2000 Society for Neuroscience $0270-6474 / 00 / 209162-12 \$ 15.00 / 0$ occurs at P12 (Blatchley et al., 1987), and from P12 to P14 the rat cochlea undergoes its most dramatic postnatal changes (Puel and Uziel, 1987; Oliver and Fakler, 1999), and the tonotopic map of the MNTB reaches adult properties by P14 (Friauf, 1992). The adult calyx morphology is also reached by P14 (Kandler and Friauf, 1993). Furthermore, several developmental shifts in expression levels of presynaptic Ca channels (Iwasaki and Takahashi, 1998), Ca-binding proteins (Lohmann and Friauf, 1996), metabotropic (Elezgarai et al., 1999), and ionotropic (Caicedo and Eybalin, 1999) glutamate receptors are completed by P14. The age from hearing onset to eye opening (P14) thus seems like a particularly interesting period in which to study developmental changes in synaptic strength and plasticity.

Here we present recordings from a single synapse as it matures during this critical developmental period. We find that presynaptic APs in P12-P14 calyxes are $66 \%$ briefer compared with P5-P7. Synaptic delays, as well as EPSC rise times and half-widths, diminished with increasing age, whereas EPSC amplitudes did not change significantly. Furthermore, P12-P14 synapses lacked the severe depression characteristic of P5-P7. Finally, increasing temperature to $35^{\circ} \mathrm{C}$ allowed some $\mathrm{P} 14$ synapses to reliably follow stimuli up to $800 \mathrm{~Hz}$. The ability to faithfully follow such high frequencies is thus because of parallel changes in both presynaptic and postsynaptic properties, which together facilitate the precise firing of this pivotal brainstem synapse.

\section{MATERIALS AND METHODS}

Slice preparation. Brainstem slices were obtained from P5 to P14 SpragueDawley rats. After decapitation, the brainstem was immersed in ice-cold low-calcium artificial CSF (aCSF) containing (in $\mathrm{mM}$ ): $\mathrm{NaCl}(125), \mathrm{KCl}$ (2.5), $\mathrm{MgCl}_{2}(3.0), \mathrm{CaCl}_{2}(0.1)$, glucose (25), $\mathrm{NaHCO}_{3}(25), \mathrm{NaH}_{2} \mathrm{PO}_{4}$ (1.25), ascorbic acid (0.4), myo-inositol (3), and Na-pyruvate (2), $\mathrm{pH} 7.3$, when bubbled with carbogen $\left(95 \% \mathrm{O}_{2}\right.$ and $\left.\mathrm{CO}_{2} 5 \%\right)$. The brainstem was glued onto the stage of a vibratome slicer, and 180- to $200-\mu \mathrm{m}$-thick transverse slices were cut proceeding from a caudal to rostral direction. Slices were rapidly transferred to an incubation chamber containing normal aCSF bubbled with carbogen and maintained at $36^{\circ} \mathrm{C}$ for $30 \mathrm{~min}$, and thereafter at room temperature. The normal aCSF was the same as the low-calcium aCSF except that $1.0 \mathrm{~mm} \mathrm{MgCl}_{2}$ and $2.0 \mathrm{mM} \mathrm{CaCl}_{2}$ were used. 
Electrophysiology. Whole-cell patch-clamp recordings were performed in normal aCSF at room temperature $\left(\mathrm{RT} ; 21-23^{\circ} \mathrm{C}\right.$ ) or at $35^{\circ} \mathrm{C}$ (Warner Instruments Heater system). The standard patch pipette solution consisted of (in mM): K-gluconate (75), $\mathrm{KCl}(75), \mathrm{Na}_{2}$-phosphocreatine (2), HEPES (10), EGTA (5), and ATP-Mg (4), pH 7.3, with KOH. To record NMDARmediated currents $\mathrm{CsCl}$ was substituted for $\mathrm{K}$-gluconate and $\mathrm{KCl}$, and 10 mM TEA was added. During experiments slices were continuously perfused with normal aCSF solution and visualized by IR-DIC microscopy through a $40 \times$ water-immersion objective (Axioskop, Zeiss, Germany) coupled to a $2 \times$ pre-magnification (Optovart; Zeiss, Oberkochen, Germany) and a CCD camera (C79; Hamamatsu, Tokyo, Japan). A bipolar stimulation electrode was placed on the brainstem midline. Visualized recordings from slices older than P11 were greatly hampered by the extensive myelinization of the brainstem. Cells were thus patched in a "semiblind" approach, after preselection of connected cells with extracellular AP recordings (Guinan and Li, 1990; Borst et al., 1995). Only cells that showed extracellular presynaptic and postsynaptic APs were chosen for whole-cell patch-clamp recordings.

Patch pipettes were pulled from soft thin-walled glass (World Precision Instruments, Sarasota, FL) using a Narishige (Tokyo, Japan) puller (PP830 ). Patch pipettes had an open tip resistance of 1.5-2.5 $\mathrm{M} \Omega$. Access resistance $\left(R_{\mathrm{s}}\right)$ ranged from 2.2 to $4.8 \mathrm{M} \Omega$ (mean, $3.6 \pm 0.2 \mathrm{M} \Omega$ ) with $\mathrm{CsCl}$-filled electrodes and slightly higher with K-gluconate-based internal solution. This low uncompensated $R_{\mathrm{s}}$ was essential for voltage-clamp recordings of the large EPSC amplitudes. $R_{\mathrm{s}}$ compensation was set to $75-90 \%$ (10 $\mu$ sec delay) depending on the initial uncompensated $R_{\mathrm{s}}$ value, producing an effective $R_{\mathrm{s}}<0.5 \mathrm{M} \Omega$. Under these conditions, EPSC amplitudes $<20 \mathrm{nA}$ produced a clamp-voltage error of $<10 \mathrm{mV}$. For voltage-clamp recordings, the time constant was estimated to be $<18 \mu \mathrm{sec}$ $\left(C_{\text {slow }}\right.$ capacitance $<36 \mathrm{pF}$; effective $\left.R_{\mathrm{s}}<0.5 \mathrm{M} \Omega\right)$. The accuracy of voltage clamp was tested in a few cells with large EPSC amplitudes by comparing the waveforms of control EPSCs with greatly reduced current responses obtained during application of $10-20 \mu \mathrm{M} 6-7$ dinitroquinoxaline-2,3-dione (DNQX) [in the presence of $50 \mu \mathrm{M}$ D,L-2 amino-5-phosphonovaleric acid (D,L-APV)]. After normalizing, the kinetics of both EPSCs was virtually indistinguishable (data not shown). Wholecell leak currents were $<300 \mathrm{pA}$ at $-70 \mathrm{mV}$ in the data set accepted for analysis. Principal cells were voltage-clamped at a holding potential of -70 $\mathrm{mV}$ if not stated otherwise. No corrections were made for liquid junction potentials.

Presynaptic and postsynaptic APs were recorded in the fast currentclamp mode of the EPC-9 after adjusting the fast-capacitance cancellation while in cell-attached mode. After break-in, the $R_{\mathrm{s}}$ value was checked in the voltage-clamped cell at -70 or $-80 \mathrm{mV}$. Current-clamp recordings were continued only if the initial uncompensated $R_{\mathrm{s}}$ was $<6 \mathrm{M} \Omega$. With a residual uncompensated capacitance of $\sim 2 \mathrm{pF}$ in the EPC-9 fast currentclamp mode (F. Sigworth, personal communication; Sigworth et al., 1995), the time constant of the current-clamp recordings was estimated to be $<12 \mu$ sec.

Stimulation pulses were applied through a Master-8 stimulator (AMPI Jerusalem, Israel) and had a duration of $100 \mu \mathrm{sec}$ and amplitudes of 2-15 V. Stimulation pulses were controlled using "Pulse" software (Heka, Lambrecht, Germany), and signals were recorded via a double EPC-9 (Heka) patch-clamp amplifier. Sampling intervals and filter settings were 10-25 $\mu \mathrm{sec}$ and $5 \mathrm{kHz}$, and $50 \mu \mathrm{sec}$ and $3.3 \mathrm{kHz}$ for AMPA- and NMDA-receptor mediated EPSCs, respectively. D,L-APV and DNQX were from Tocris Cookson (Bristol, UK). All other salts and chemicals were from Sigma. Offline analysis was done with "IgorPro" software (Wavemetrics, Lake Oswego, OR). Average data are reported as mean $\pm \mathrm{SE}$ values.

\section{RESULTS}

\section{Presynaptic and Postsynaptic APs: changes in waveform and timing precision}

The calyx of Held synapse consists of a single, large terminal that contacts the soma of one principal cell of the MNTB. During postnatal development, the presynaptic terminal undergoes extensive morphological changes (Kandler and Friauf, 1993) reaching an adult-like morphology at P14. We first investigated whether this morphological reorganization was accompanied by functional changes in the presynaptic AP waveform. For this purpose we recorded presynaptic APs evoked by afferent fiber stimulation at various stimulation frequencies $(10-800 \mathrm{~Hz})$. These are physiologically relevant frequencies because spontaneous rates recorded in single afferent fibers of the trapezoid body range from 10 to $80 \mathrm{~Hz}$ (Spirou et al., 1990). Moreover, rates driven by sound stimulation can range from 100 to $700 \mathrm{~Hz}$ in adult cats (Rhode and Smith, 1986; Spirou et al., 1990; Smith et al., 1998). Whole-cell recordings were confirmed to be presynaptic by the following three criteria: first, afferent stimulation evoked short-latency all-or-none APs or "action currents", under current-clamp or voltage-clamp conditions, respectively (Forsythe, 1994). These were followed by characteristic small, postsynaptic potentials (elicited by APs in the capacita- tively coupled postsynaptic cells), which increased in latency after high-frequency stimulation. Second, the recording exhibited a complete absence of spontaneous miniature EPSCs. Finally, presynaptic terminals had higher input resistance and more negative resting membrane potential (approximately $-80 \mathrm{mV}$ ). Examples of presynaptic AP waveforms for $\mathrm{P} 7, \mathrm{P} 10$, and $\mathrm{P} 14$ slices are illustrated in Figure $1 A$. Mean AP amplitudes were similar throughout development (P5-P7, $117 \pm 2 \mathrm{mV}, n=7$; P8-P11, $120 \pm 2 \mathrm{mV}, n=8$; $\left.\mathrm{P} 12-\mathrm{P} 14,126 \pm 2 \mathrm{mV}, n=4 ; V_{\mathrm{r}},-80 \mathrm{mV}\right)$. However, the AP half-width was reduced by approximately two-thirds for P12-P14 calyxes (P5-P7, $564 \pm 40 \mu \mathrm{sec}$; P8-P11, $334 \pm 26 \mu$ sec; P12-P14, $191 \pm 8 \mu \mathrm{sec})$, and the maximum rate of rise had almost doubled at P12-P14 (P5-P7, $630 \pm 50 \mathrm{mV} / \mathrm{msec} ; \mathrm{P} 8-\mathrm{P} 11,820 \pm 40 \mathrm{mV} /$ msec; P12-P14: $1108 \pm 10 \mathrm{mV} / \mathrm{msec})$. By comparison, cerebellar granule cell presynaptic APs have a half-width of $1.5 \mathrm{msec}$ at RT (Sabatini and Regehr, 1997). Extremely narrow APs (half-width of $0.25 \mathrm{msec}$ at $37^{\circ} \mathrm{C}$ ) are also observed in the rat nodes of Ranvier, which contain a very high density of $\mathrm{Na}^{+}$channels (Schwarz and Eikhof, 1987).

Presynaptic P12-P14 APs also had a more pronounced afterhyperpolarization followed by a small afterdepolarization. The slow afterdepolarization was previously suggested to originate from the charging of the electrical capacitance of the large-diameter axon (Borst et al., 1995). It is conceivable that the myelinization starting at P8 in rat MNTB (K. Kandler and E. Friauf, personal communication), may reduce the capacitance of the axon. However, as shown in Figure $1 A$, we did not observe a significant change in the presynaptic AP afterdepolarization with age.

Presynaptic whole-cell current-clamp recordings illustrated in Figure $1 A$ were obtained with $5 \mathrm{~mm}$ EGTA in the patch pipette. To clarify whether this concentration of mobile $\mathrm{Ca}^{2+}$ buffer could uncouple $\mathrm{Ca}^{2+}$-activated $\mathrm{K}^{+}$conductances and thereby slow the time course of the presynaptic AP, we conducted additional experiments with a lower EGTA concentration in the internal solution (0.2 mm; Borst and Sakmann, 1996). As shown in Figure 2B, this 25 -fold lower $\mathrm{Ca}^{2+}$ buffer concentration did not affect the presynaptic AP waveform. Using 0.2 instead of $5 \mathrm{~mm}$ EGTA in the pipette solution, we obtained similar average values for AP amplitude $(\mathrm{P} 5-\mathrm{P} 7,115 \pm 2 \mathrm{mV}, n=5 ; \mathrm{P} 8-\mathrm{P} 11,124 \pm 3 \mathrm{mV}, n=4)$, half-width (P5-P7, $504 \pm 27 \mu$ sec; P8-P11, $323 \pm 25 \mu \mathrm{sec})$, and rate of rise (P5-P7, $668 \pm 17 \mathrm{mV} / \mathrm{msec}$; P8-P11, $894 \pm 32 \mathrm{mV} /$ msec) ( $p>0.05$, two-tailed Student's $t$ test).

An example of P7 APs elicited by afferent fiber stimulation at 10 $\mathrm{Hz}$ is illustrated in Figure $1 C$. At all ages, the fluctuation in the exact timing of the AP peak ("jitter") was $<50 \mu \mathrm{sec}$ at this stimulation frequency. At RT, AP generation in presynaptic calyxes could follow stimulation frequencies up to $200-300 \mathrm{~Hz}$, but failed at $400 \mathrm{~Hz}$ or higher in P5-P7 slices. In contrast, frequencies up to $500 \mathrm{~Hz}(\mathrm{RT})$ or up to $800 \mathrm{~Hz}\left(35^{\circ} \mathrm{C}\right)$ were faithfully followed in P12-P14 calyxes (data not illustrated).

Examples of individual postsynaptic APs for P6 and P13 are shown in Figure $1 D$. Compared with calyceal APs, postsynaptic APs were generally smaller in amplitude and had a slower time course. In addition, similarly to the presynaptic terminal we also observed a shortening of the AP waveforms in the postsynaptic neuron during development, whereas AP amplitudes did not significantly change [Fig. $1 D$; average values at P5-P7 $(n=11)$ versus P12-P14 $(n=10)$ for AP amplitudes, $100 \pm 2 \mathrm{mV}$ versus $104 \pm 2$ $\mathrm{mV}$; half-width, $980 \pm 72 \mu \mathrm{sec}$ versus $457 \pm 15 \mu \mathrm{sec}$, maximum rate of rise, $377 \pm 23 \mathrm{mV} / \mathrm{msec}$ versus $582 \pm 31 \mathrm{mV} / \mathrm{msec} ; V_{\mathrm{r}}$ approximately $-70 \mathrm{mV}$ ]. However, the timing pattern of postsynaptic APs during repetitive stimulation was profoundly different for both ages. For example, the P6 synapse of Figure $1 E$ had a latency between the presynaptic prepotential (defined below) and the peak of postsynaptic APs that ranged from 1 to $>4 \mathrm{msec}$ (mean latency of $2.90 \mathrm{msec}$ ). This occurred despite the fact that presynaptic APs at P5-P7 had a jitter in peak timing of $<50 \mu$ s (Fig. 1C). By contrast, the P13 synapse illustrated in Figure $1 F$ had a mean latency of $0.58 \mathrm{msec}$ (range, $0.42-0.66 \mathrm{msec}$ ). In Figure $1 G$, latency histograms obtained from pooled data of 6 (P5-P7) and 4 (P12- 

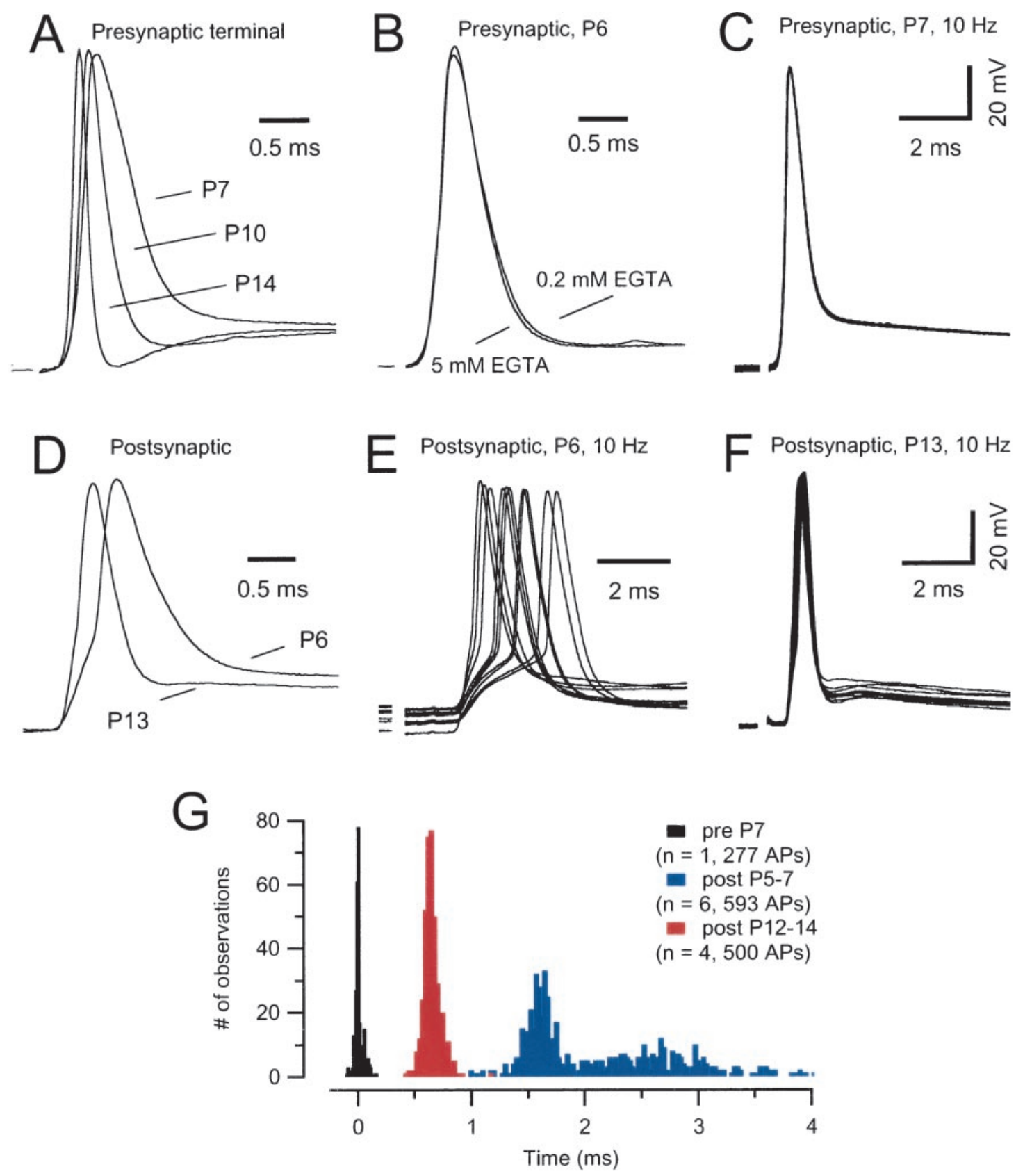

Figure 1. Developmental changes in waveform and timing of presynaptic and postsynaptic APs at the calyx of Held synapse. $A$, Current-clamp whole-cell recordings of presynaptic APs in brainstem slices at P7, P10, and P14. APs were evoked by afferent fiber stimulation. Note the faster kinetics and shorter duration of the APs and the presence of a fast afterhyperpolarization in older calyxes. $B$, Presynaptic AP waveform for two different P6 calyxes. One calyx was dialyzed with $0.2 \mathrm{~mm}$ EGTA, whereas the other was dialyzed with $5 \mathrm{~mm}$ EGTA. $C$, Consecutive responses to a train of afferent stimuli (10 Hz) recorded in a presynaptic terminal at $\mathrm{P} 7$ (same neuron as in $A$, first 10 responses). $D$, Comparison of AP waveforms in postsynaptic MNTB neurons in $\mathrm{P} 6$ and P13 slices. $E, F$, Consecutive responses to afferent stimulation at $10 \mathrm{~Hz}$ (same neurons as in $D$, first 10 responses). $G$, Latency distribution of APs elicited at $10 \mathrm{~Hz}$. Pooled data from P5-P7 $(n=6)$ and P12-P14 $(n=4)$ slices. Latency was calculated as the time from negative peak of the prepotential to the peak of the postsynaptic APs. During development, the latency between presynaptic and postsynaptic APs decreased and the jitter in AP timing was reduced. Mean latency was $2.09 \pm 0.24$ and $0.64 \pm 0.03 \mathrm{msec}$ for P5-P7 and P12-P14 slices, respectively. Latency distribution of the presynaptic APs is shown for comparison (same neuron as in $C$ ). K-gluconate-filled electrodes were used and experiments were done at room temperature. The resting membrane potential $\left(V_{\mathrm{r}}\right)$ was -80 and $-70 \mathrm{mV}$ for presynaptic and postsynaptic neurons, respectively. Stimulus artifacts were blanked for clarity.

P14) principal cells are shown. For each neuron, the timing of the presynaptic AP was estimated from the prepotential in the respective voltage-clamp recording. The distributions are strikingly different and do not overlap. For comparison, the latency distribution for the calyceal APs shown in Figure $1 C$ is given (normalized to time 0$)$. It is evident that the fidelity by which timing information is being transmitted has greatly increased from P5 to P7 and from P12 to P14. This agrees well with previous recordings that tested $0.2 \mathrm{~Hz}$ stimulation frequencies in $\mathrm{P} 4$ and $\mathrm{P} 9-\mathrm{P} 10$ rats (Chuhma and Ohmori, 1998).
We next tested at various stages of development whether afferent fiber stimulation at high frequencies $(>100 \mathrm{~Hz})$ could reliably evoke postsynaptic APs. Figure 2, $A$ and $B$, illustrates currentclamp recordings after afferent fiber stimulation with $100 \mathrm{~Hz}$ trains for P5 and P14 postsynaptic neurons. Both experiments were performed at RT. At P5 typically only the first two or three EPSPs were suprathreshold. A pronounced AP adaptation and large plateau depolarization was observed. In contrast, the same $100 \mathrm{~Hz}$ stimulation triggered well timed and large postsynaptic APs during the whole train without a decline in AP amplitude in the P14 


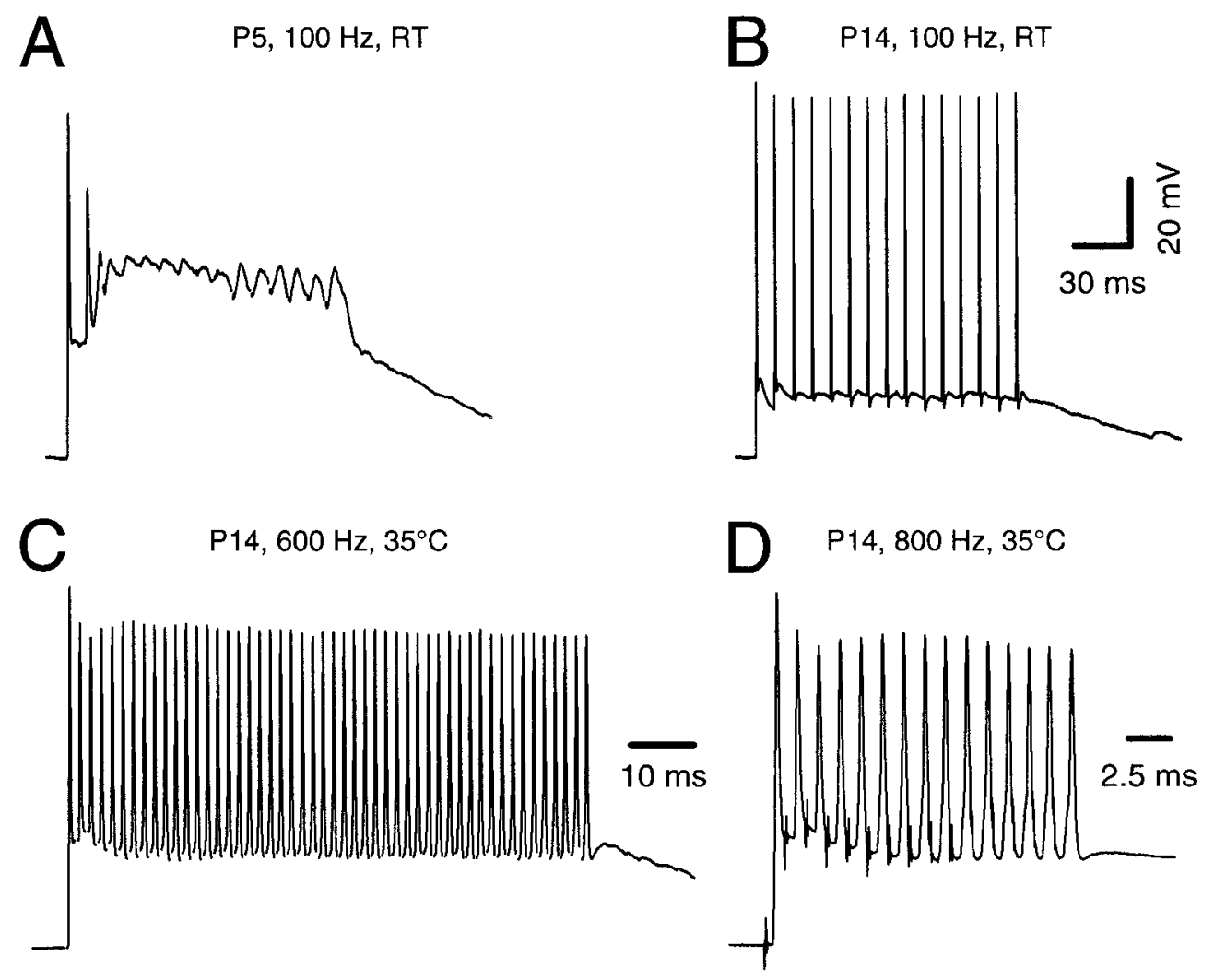

Figure 2. The capacity for highfrequency transmission is fully established by the end of the second postnatal week. $A, B$, Postsynaptic APs in response to trains of 15 stimuli $(100 \mathrm{~Hz})$ recorded in $\mathrm{P} 5(A)$ and $\mathrm{P} 14(B)$ brainstem slices at room temperature. At P5, usually only the first two to three EPSPs were suprathreshold and generated APs in the postsynaptic neuron. Note the strong AP adaptation and large plateau depolarization at P5, which are both absent at P14. C, D, Current-clamp recordings at near physiological temperature $\left(35^{\circ} \mathrm{C}\right)$. In $\mathrm{P} 12-\mathrm{P} 14$ slices, reliable synaptic transmission was generally possible at frequencies up to 600 $\mathrm{Hz}$ under these conditions (50 stimuli; $C$ ). Occasionally, postsynaptic neurons were able to respond to afferent stimulation up to $800 \mathrm{~Hz}$ without failures of AP generation (15 stimuli; $D)$. K-gluconate-filled electrodes. $V_{\mathrm{r}}$ was approximately -70 $\mathrm{mV}$. Notice that for the $800 \mathrm{~Hz}$ frequency the exact timing of the APs late in the train becomes less precise, as evidenced by the stimulus artifact falling progressively further into the down stroke phase of the preceding spike $(D)$. neuron. Furthermore, the large plateau depolarization, presumably because of a summation of slow NMDAR-mediated EPSPs (see below), was significantly reduced at P14 (Forsythe and BarnesDavies, 1993; Zhang and Trussell, 1994a). In fact, at RT this same P14 neuron could reliably generate APs for stimulation frequencies of up to $400 \mathrm{~Hz}$ throughout the stimulus train. When the bath temperature was increased to more physiological values $\left(35^{\circ} \mathrm{C}\right)$, the frequency range for reliable synaptic transmission was greatly expanded. At $35^{\circ} \mathrm{C}$ principal cells followed input frequencies of up to $600 \mathrm{~Hz}$ for long tetanic stimulation (50 stimuli, Fig. $2 C ; n=5$ cells) and up to $700-800 \mathrm{~Hz}$ for shorter trains (15 stimuli, Fig. $2 D ; n=$ 3 cells).

\section{Decrease in NMDAR-mediated EPSC amplitudes}

We next characterized the underlying synaptic currents responsible for triggering the postsynaptic APs of Figures 1 and 2. Afferent stimulation evokes dual-component EPSCs in principal cells of the MNTB (Forsythe and Barnes-Davies, 1993). In many glutamatergic synapses the ratio of slow NMDAR-mediated $\left(I_{\mathrm{NMDA}}\right)$ to fast AMPAR-mediated $\left(I_{\text {AMPA }}\right)$ EPSC component decreases with development (Hestrin, 1992; Shi et al., 1997; Bellingham et al., 1998). We therefore investigated whether the size of synaptic NMDAR current changed from P5 to P14 at the calyx of Held synapse. Both EPSC components were isolated by measuring their peak amplitudes at $-75 \mathrm{mV}$ and at $+50 \mathrm{mV}$ for $I_{\mathrm{AMPA}}$ and $I_{\mathrm{NMDA}}$, respectively. Figure $3, A$ and $B$, illustrates families of EPSCs recorded from P6 (Fig. $3 A$ ) and P14 (Fig. $3 B$ ) at various holding potentials. Although EPSC peak amplitudes at $V_{\mathrm{h}}=-75 \mathrm{mV}$ were comparable for both ages, amplitudes of $I_{\mathrm{NMDA}}$ were largely reduced at P14. In addition, the NMDAR-mediated EPSC decayed faster for P14 compared with P6 as is evident from Figure $3 C$, showing both current responses normalized and superimposed. This faster decay of NMDA EPSCs is indicative of a developmental change from NMDA receptor channels containing NR2B subunits to those containing NR2A subunits with age (Flint et al., 1997). As summarized in Figure $3 D$, mean amplitudes of AMPA EPSC did not change significantly with development (Table 1), whereas NMDA EPSCs were on average reduced by $\sim 50 \%(15.4 \pm 2.9$ vs $7.8 \pm 1.1$
nA) from P5-P7 $(n=5)$ to P12-P14 $(n=8)$. Thus, the ratio $I_{\mathrm{NMDA}}: I_{\mathrm{AMPA}}$ decreased considerably in older slices (Table 1$)$.

In current-clamp recordings, high-frequency $(>100 \mathrm{~Hz})$ afferent stimulation produced a long-lasting depolarization in postsynaptic MNTB neurons that was especially pronounced in P5-P7 slices (Fig. 2A). Presumably this was caused by summation of slow NMDA receptor-mediated EPSPs during the trains. Given the large amplitude of $I_{\mathrm{NMDA}}$ in P5-P7 animals, it is conceivable that this prolonged depolarization could progressively inactivate $\mathrm{Na}$ channels and thereby prevent repetitive AP generation. We therefore asked whether blocking NMDA receptor activation affects the number of APs generated during a stimulus train. Figure $3 E$ illustrates a P6 synapse stimulated at $100 \mathrm{~Hz}$ in the absence and presence of $50 \mu \mathrm{M}$ D,L-APV, a specific blocker of $I_{\text {NMDA }}$ (Fig. $3 E$, inset). Although APV greatly reduced the plateau depolarization, blocking $I_{\mathrm{NMDA}}$ did not affect the number of APs generated during afferent fiber stimulation. However, the same neuron was able to generate trains of APs after injection of depolarizing current pulses $(100 \mathrm{~Hz}, 1 \mathrm{msec}$ pulses of $1 \mathrm{nA}$; data not shown). Nevertheless, it is conceivable that $\mathrm{Na}$ channel inactivation caused by the slow plateau depolarization may contribute to the reduction in AP amplitude as seen in Figures $2 A$ and $3 E$. By contrast, in P14 animals, APV caused only a small reduction in the plateau depolarization (Fig. 3F). This suggests that although there is still a significant amount of $I_{\mathrm{NMDA}}$ at P14, it plays a gradually diminishing role during the first 2 weeks of postnatal development.

\section{Shortening of synaptic delays and faster kinetics of AMPAR-mediated EPSC}

The timing of the postsynaptic APs is primarily determined by the synaptic delay as well as the amplitude and kinetics of the fast AMPAR-mediated EPSC. We therefore measured synaptic delays and quantified changes in kinetics of $I_{\mathrm{AMPA}}$ as a function of age. The synaptic delay was determined from the negative peak of the prepotential to the beginning of the EPSC (20\% rise time point). The prepotential is a biphasic reflection of the calyx AP, and can usually be clearly detected in postsynaptic voltage-clamp recordings. Its negative peak coincides with the maximum rate of rise of 


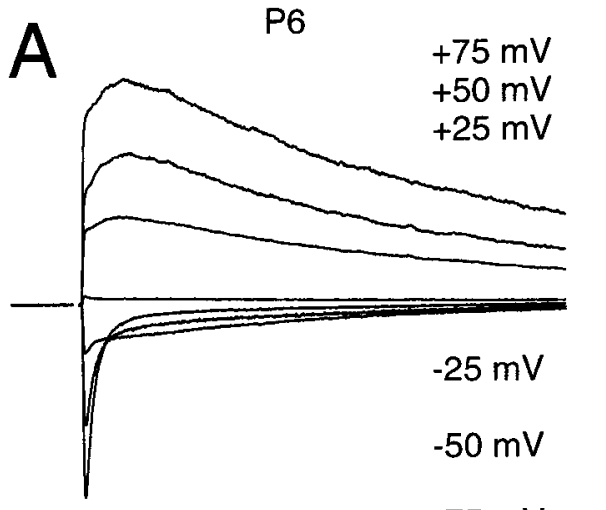

$-75 \mathrm{mV}$

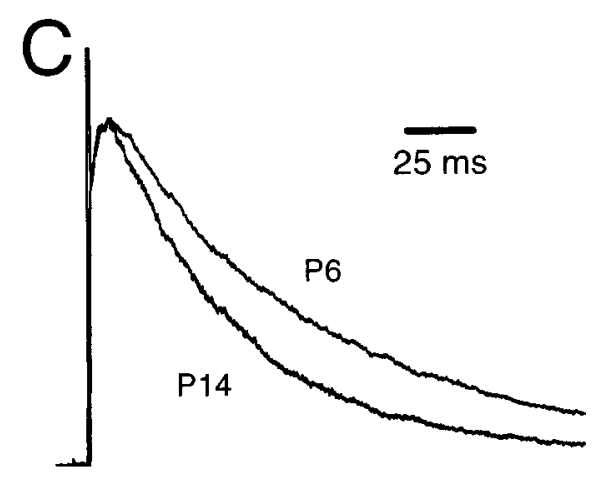

Figure 3. During postnatal development, NMDA receptor-mediated EPSCs decreased in amplitude and acquired faster kinetics. $A, B$, Families of evoked EPSCs were recorded at various holding potentials ( $V_{\mathrm{h}}$, as indicated) in P6 $(A)$ and P14 $(B)$ brainstem slices. At P14, amplitudes of $I_{\mathrm{NMDA}}$ were largely reduced, whereas $I_{\text {AMPA }}$ remained approximately constant throughout development. $C$, Same neurons as depicted in $A$ and $B$. To facilitate comparison, EPSCs evoked at $V_{\mathrm{h}}=+50 \mathrm{mV}$ are shown superimposed. Current responses were normalized and aligned at their peak amplitudes of $I_{\text {NMDA. }} D$, Summary data of five and eight different cells for P5-P7 and P12-P14, respectively. Mean amplitudes of peak $I_{\mathrm{AMPA}}$ were $-13.76 \pm 1.36$ and $-12.96 \pm 1.25 \mathrm{nA}$ $\left(V_{\mathrm{b}}=-75 \mathrm{mV}\right)$, and mean amplitudes of peak $I_{\text {NMDA }}$ were $15.4 \pm 2.92$ and $7.8 \pm 1.06 \mathrm{nA}$ $\left(V_{\mathrm{h}}=+50 \mathrm{mV}\right)$ for P5-P7 and P12-P14, respectively. $E, F$, Current-clamp recordings of postsynaptic APs evoked by afferent fiber stimuli $(100 \mathrm{~Hz})$ under control conditions and during application of $50 \mu \mathrm{M} \mathrm{D,L}-\mathrm{APV}\left(V_{\mathrm{r}}=-70\right.$ $\mathrm{mV})$. $E$, At P6 ( $n=6$ cells), APV strongly reduced the large plateau depolarization but had no effect on the number of APs generated during the stimulus train. Inset, Voltage-clamp recordings $\left(V_{\mathrm{h}}=-30 \mathrm{mV}\right)$ from the same cell; AMPA EPSCs truncated for clarity. $F$, At P14, $50 \mu \mathrm{M}$ D,L-APV had little effect on postsynaptic responses. $\mathrm{CsCl}$ and $\mathrm{K}$-gluconate-based internal solutions were used in the experiments illustrated in $A-D$ and $E$ and $F$, respectively.

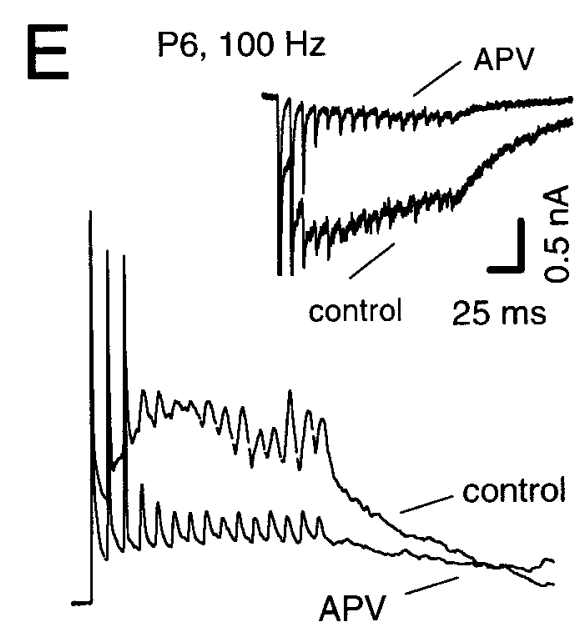

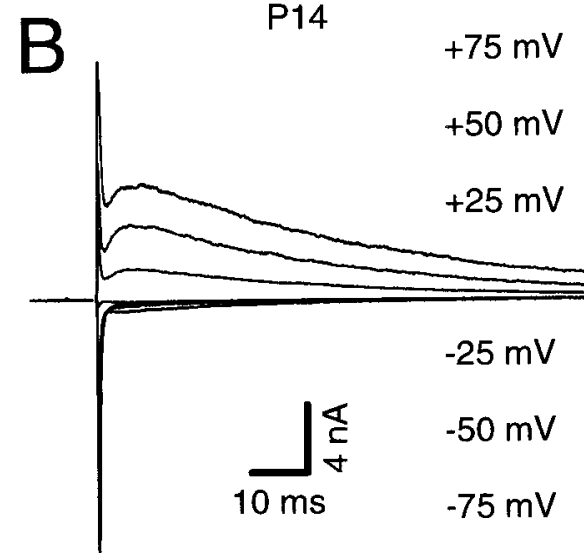

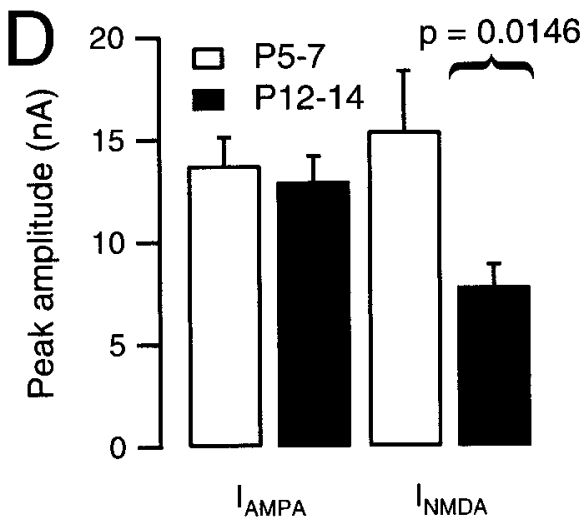

$E$

$\mathrm{P} 14,100 \mathrm{~Hz}$

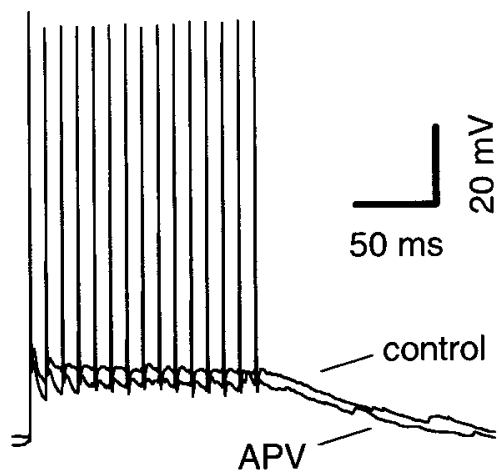

the presynaptic AP (Borst et al., 1995). Figure 4, $A$ and $B$, exemplifies EPSCs for P7 and P14 and illustrates the shortening of synaptic delays from P7 to P14 cells. Both traces were aligned at the lower peak of the prepotential that is marked with a dashed line. On average, the synaptic delay was reduced by $291 \mu \mathrm{sec}$ from P5-P7 to P12-P14 (Table 1). To facilitate comparison of their waveforms, the EPSCs were aligned at their initial rise and normalized in Figure $4 B$. Notice that both rise time and decay of the EPSCs were faster for P14 than for P7. In Figure 4, the 20-80\% rise times $(C)$, half-widths $(D)$, and EPSC amplitudes $(E)$ of our full data set are plotted as a function of age. Measured rise times and half widths ranged from 107 to $259 \mu \mathrm{sec}$ (mean, $162 \pm 3 \mu \mathrm{sec}$; $n=155$ ) and from 251 to $1694 \mu \mathrm{sec}$ (mean, $758 \pm 27 \mu \mathrm{sec} ; n=155$ ). Although there was some cell to cell variability, a highly significant developmental trend toward shorter rise times and half-widths is evident (see also Table 1 for comparison of P5-P7 to P12-P14). EPSC amplitudes ranged from -1.3 to $-19.7 \mathrm{nA}$ (mean, $-9.1 \pm$
$0.3 \mathrm{nA} ; n=155)$ and exhibited a large variability at all ages. The small increase in mean EPSC amplitudes with age was not significant.

\section{Changes in kinetics and latencies of evoked quantal EPSCs}

In addition to channel kinetics, the waveform of evoked EPSCs at different synapses is shaped by asynchronous release of individual quanta (Katz and Miledi, 1965; Diamond and Jahr, 1995; Isaacson and Walmsley, 1995). At the calyx of Held synapse a single EPSC is composed of $\sim 200$ quantal events (Borst and Sakmann, 1996). A variable degree of asynchrony in the presynaptic release process could thus have a profound impact on the EPSCs kinetics. Indeed, a large amount of jitter in the timing of EPSCs has been reported for very young (P4) rats (Chuhma and Ohmori, 1998).

To estimate the contribution of asynchronous release to differences in EPSC kinetics, we recorded miniature EPSCs (mEPSCs) 
Table 1. Developmental changes in synaptic delay, EPSC kinetics, and short-term plasticity at the calyx of Held synapse

\begin{tabular}{|c|c|c|c|}
\hline Parameter & P5-P7 & P12-P14 & \\
\hline \multicolumn{4}{|l|}{ EPSC } \\
\hline Synaptic delay & $795.4 \pm 26.1 \mu \sec (n=26)$ & $504.2 \pm 15.9 \mu \sec (n=18)$ & $p<0.001$ \\
\hline EPSC amplitude & $9.60 \pm 0.56 \mathrm{nA}(n=34)$ & $10.66 \pm 0.82 \mathrm{nA}(n=34)$ & $p=0.142$ \\
\hline EPSC rise time $(20-80 \%)$ & $208.4 \pm 4.7 \mu \sec (n=34)$ & $127.1 \pm 2.4 \mu \sec (n=34)$ & $p<0.001$ \\
\hline EPSC half-width & $1123.4 \pm 49.7 \mu \sec (n=34)$ & $433.9 \pm 18.7 \mu \sec (n=34)$ & $p<0.001$ \\
\hline \multicolumn{4}{|c|}{ EPSC decay (exponential time constants) } \\
\hline$\tau_{\text {fast }}$ & $1.28 \pm 0.04 \mu \sec (n=24)$ & $0.44 \pm 0.02 \mu \sec (n=25)$ & $p<0.001$ \\
\hline$\tau_{\text {slow }}$ & $7.06 \pm 0.60 \mu \sec (n=24)$ & $4.21 \pm 0.19 \mu \sec (n=25)$ & $p<0.001$ \\
\hline Ratio $I_{\mathrm{NMDA}} / I_{\mathrm{AMPA}}$ & $-1.08 \pm 0.11(n=5)$ & $-0.62 \pm 0.07(n=8)$ & $p<0.001$ \\
\hline \multicolumn{4}{|l|}{ Degree of depression } \\
\hline $10 \mathrm{~Hz}$ & $84.5 \pm 0.9 \%(n=23)$ & $55.0 \pm 2.0 \%(n=23)$ & $p<0.001$ \\
\hline $100 \mathrm{~Hz}$ & $97.2 \pm 0.3 \%(n=23)$ & $71.6 \pm 2.8 \%(n=23)$ & $p<0.001$ \\
\hline $300 \mathrm{~Hz}$ & $99.1 \pm 0.1 \%(n=14)$ & $85.8 \pm 2.8 \%(n=19)$ & $p<0.001$ \\
\hline \multicolumn{4}{|l|}{ Evoked quantal EPSC } \\
\hline Synaptic delay & $\begin{array}{l}985.9 \pm 7.5 \mu \mathrm{sec} \\
(n=4 \text { cells, } 727 \text { events })\end{array}$ & $\begin{array}{l}668.7 \pm 7.3 \mu \mathrm{sec} \\
(n=4 \text { cells, } 550 \text { events })\end{array}$ & $p<0.01$ \\
\hline EPSC amplitude & $70.6 \pm 6.9 \mathrm{pA}(n=4)$ & $79.5 \pm 7.0 \mathrm{pA}(n=4)$ & $p=0.201$ \\
\hline EPSC rise time $(20-80 \%)$ & $211.3 \pm 9.6 \mu \sec (n=4)$ & $149.3 \pm 10.5 \mu \sec (n=4)$ & $p<0.01$ \\
\hline EPSC half-width & $966.9 \pm 126.6 \mu \sec (n=4)$ & $516.8 \pm 47.1 \mu \sec (n=4)$ & $p<0.05$ \\
\hline
\end{tabular}

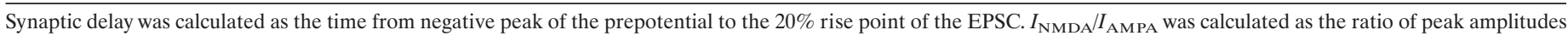

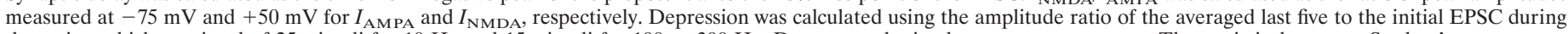
the trains, which consisted of 25 stimuli for $10 \mathrm{~Hz}$ and 15 stimuli for 100 or $300 \mathrm{~Hz}$. Data were obtained at room temperature. The statistical test was Student's $t$ test.

and also evoked quantal EPSCs under conditions of strongly reduced probability of release $\left(50 \mu \mathrm{M} \mathrm{Cd}{ }^{2+}\right.$ added to the external solution; Isaacson and Walmsley, 1995). Under these conditions maximum EPSC amplitudes evoked by afferent fiber stimulation were $<200 \mathrm{pA}$, and many stimuli failed to evoke a response (average failure rate $30 \%$ ). However, the prepotentials were unaffected by $50 \mu \mathrm{M} \mathrm{Cd}^{2+}$, indicating that failures of glutamate release were not caused by failures of presynaptic AP propagation or

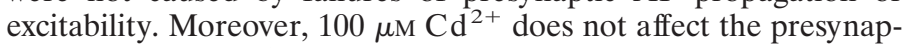
tic AP waveform (Borst et al., 1995). We preferred to analyze evoked quantal EPSCs as opposed to spontaneous mEPSCs, because principal cells of the MNTB receive numerous non-calyceal excitatory inputs (Banks and Smith, 1992; Forsythe and BarnesDavies, 1993; Smith et al., 1998). Excitatory inputs that could be identified as non-calyceal by their much longer latencies and slower kinetics were noticed in several recordings, especially from more mature slices (data not shown). By recording evoked calyceal quantal EPSCs we thus excluded these events generated from bouton-type terminals from our analysis.

Examples of mEPSCs and evoked quantal EPSCs for P5 and P14 are shown in Figure $5 A-D$. Notice the large variability in amplitude at both ages but the much faster current kinetics at P14. Because we were interested in determining the exact kinetics and latency of quantal responses, events with amplitudes $>20 \mathrm{pA}$ were selected, and rarely occurring EPSCs $>150 \mathrm{pA}$ were discarded. This amplitude range corresponded to that observed for spontaneous mEPSCs (Fig. 5A,C). Moreover, these evoked quantal events had clearly defined monotonic rise times, with relatively little contamination from baseline noise. Similarly to control EPSCs (Fig. 4A), evoked quantal EPSCs had shorter synaptic delays for P14 compared with P5 (Fig. 5B,C). However, at both ages, individual quantal events occurred stochastically within a comparably narrow time window. Furthermore, evoked quantal EPSCs had much faster rise and decay at P14 compared with P7. Figure $5 E$ shows the average quantal EPSC obtained from unaligned (solid line) and aligned (at their 50\% rise point, dotted line) evoked events. For the P5 cell shown in Figure 5E, mean peak amplitude, $20-80 \%$ rise time, and the half-width were $-62 \mathrm{pA}, 221 \mu \mathrm{sec}, 1406 \mu \mathrm{sec}$, and $-59 \mathrm{pA}, 310 \mu \mathrm{sec}$, and $1477 \mu \mathrm{sec}$ for aligned and unaligned events, respectively. The corresponding values for the P14 cell amounted to $-72 \mathrm{pA}, 127 \mu \mathrm{sec}, 441 \mu \mathrm{sec}$, and $-62 \mathrm{pA}, 176 \mu \mathrm{sec}$, and 541 $\mu$ sec for aligned and unaligned events, respectively. For both ages, average EPSC waveforms obtained from aligned quantal events thus rose and decayed more quickly than those computed from unaligned quantal events, as expected from previous findings for P8-P10 rats (Borst and Sakmann, 1996).

To compare the variability of synaptic delays at both ages, synaptic latencies were obtained for a total of four cells $(>100$ quantal events/cell) in each age group. Latency histograms of the pooled data are shown in Figure $5 F$ (Barrett and Stevens, 1972). The two histograms were temporally shifted by the difference in average synaptic delay, and when they were superimposed, the P5-P7 histogram was slightly wider than the P12-P14 histogram. The mean variance of the synaptic delays was smaller for P12-14 $\left(0.019 \pm 0.006 \mathrm{msec}^{2} ; n=4\right)$ compared with P5-P7 (0.037 \pm 0.005 $\left.\operatorname{msec}^{2} ; n=4\right)(p=0.003$; Student's $t$ test $)$. This suggests that a smaller degree of asynchrony in glutamate release may additionally contribute to the faster EPSC kinetics in older animals.

\section{Reduced synaptic depression and larger vesicle pool size}

We next studied the developmental changes in frequencydependent depression of EPSCs. Recordings with similar initial peak amplitude from P6 and P14 slices are shown in Figure 6. For P6 robust synaptic depression was induced already at $10 \mathrm{~Hz}$ stimulation, and steady-state depression was $>95 \%$ for $100 \mathrm{~Hz}$ (Fig. $6 A, B)$. In contrast, the degree of depression was greatly reduced at $\mathrm{P} 14$ at the same stimulation frequencies (Fig. 6C,D). At this age, the synapses were generally capable of transmitting at high stimulus frequencies of $300 \mathrm{~Hz}$ in RT (Fig. $6 E$ ) and sometimes up to $500 \mathrm{~Hz}$ (Fig. $6 F$ ). The P14 EPSC of Figure $6 C$, for example, had an initial peak amplitude of $13.3 \mathrm{nA}$. After 15 stimuli in a $100 \mathrm{~Hz}$ train, the last EPSC still had a large amplitude of $5.4 \mathrm{nA}$. By contrast, the P6 cell at $100 \mathrm{~Hz}$ (Fig. 6B) started with a comparable amplitude of 14 $\mathrm{nA}$, but was reduced to $0.21 \mathrm{nA}$ by the fourth EPSC in the train. The degree of steady-state depression elicited by high-frequency stimulation was thus greatly reduced with age. Nevertheless, for sufficiently high frequencies (e.g., $500 \mathrm{~Hz}$, Fig. $6 F$ ), a severe synaptic depression could still be induced even in P14 synapses.

Average data for 115 different cells tested at $10 \mathrm{~Hz}$ between postnatal days 5 and 14 are illustrated in Figure $7 A$. Although the degree of synaptic depression was variable at any given stage of 

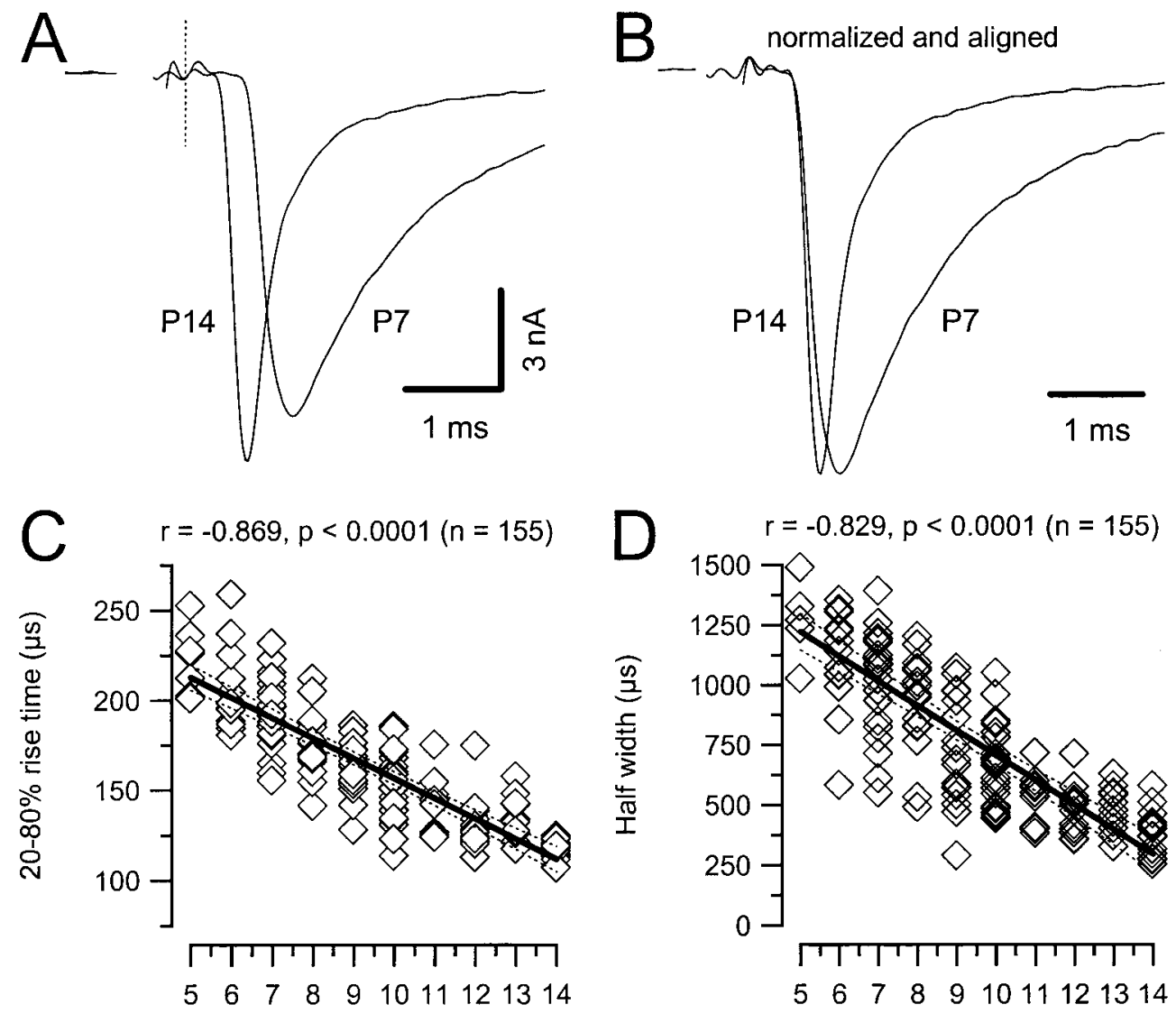

Postnatal days

Figure 4. Developmental changes in synaptic current kinetics for AMPA receptormediated EPSCs. $A$, Sample EPSCs recorded in P7 and P14 brainstem slices $\left(V_{\mathrm{h}}=-70 \mathrm{mV}\right)$. Current responses were aligned at the negative peak of the prepotential (dotted line). Note the shorter synaptic delay and faster time course at P14. B, Same responses as depicted in $A$. To facilitate comparison, amplitudes were normalized, and EPSCs were aligned at their onsets. $C-E$, Pooled data for EPSC rise times $(C)$, half widths $(D)$, and peak amplitudes $(E)$ from a total of $>130$ cells plotted versus postnatal age. Solid and dotted lines indicate linear regression and $99 \%$ confidence limits, respectively. Regression coefficients and number of cells as indicated at each panel. Both EPSC rise times and half widths decreased significantly $(p<0.0001)$ during development. In contrast, only little increase in EPSC peak amplitudes was observed $(p>0.05)$.

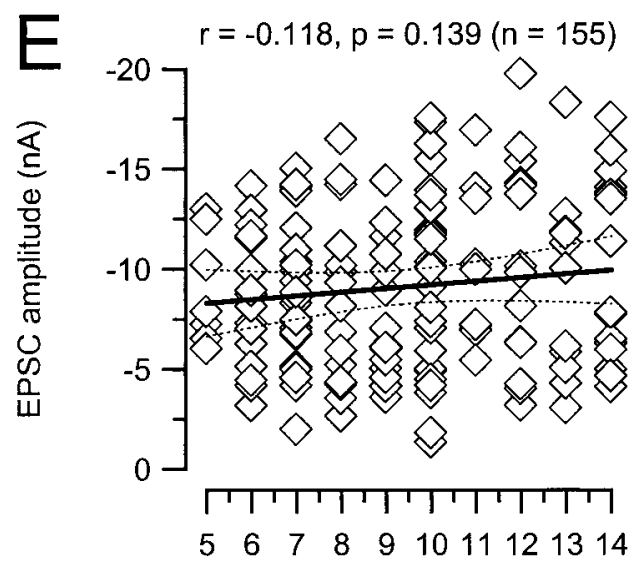

development, there was a clear developmental trend toward less depression. This trend was statistically highly significant. On average, the depression measured at $10 \mathrm{~Hz}$ decreased from $84 \%$ (P5) to $56 \%$ (P14). With regard to the variability of depression portrayed in Figure $7 A$, it is noteworthy that the MNTB is not a homogeneous nucleus of cells, but in fact has a tonotopically organized map of best frequency cells (Friauf, 1992).

In a subset of cells, we further tested depression for stimulus frequencies of 100 and $300 \mathrm{~Hz}$. Average data of these experiments are illustrated in Figure 7B. At P5-P7, steady-state depression was already reached with the fifth stimuli at 10 and $100 \mathrm{~Hz}$, whereas at P12-P14 at least 10 stimuli were needed to reach steady state at 300 $\mathrm{Hz}$. At this age, a $30 \times$ higher stimulation frequency was necessary to achieve a comparable degree of steady-state depression as seen with $10 \mathrm{~Hz}$ at P5-P7. The degree of steady-state depression is thus strongly regulated during development.

Postnatal days

Assuming that vesicle pool depletion accounts for most of the severe depression at $100 \mathrm{~Hz}$ for $\mathrm{P} 6$, and the strong depression at $300 \mathrm{~Hz}$ for P14, we next estimated the size of the readily releasable pool of synaptic vesicles for the two age groups. As an index of vesicle pool size we used the cumulative EPSC amplitude (Schneggenburger et al., 1999). The results of this analysis are shown in Figure $7 C$. The summed P5-P7 EPSC amplitudes (represented by open triangles; same data as in Fig. $7 B$ ) quickly reached a plateau value. A linear fit over the last points during the train was then back-extrapolated to yield an estimate for the initial pool size proportional to $12 \mathrm{nA}$. A similar analysis for $100 \mathrm{~Hz}$ (solid triangles) and $300 \mathrm{~Hz}$ (solid circles) gives values of 25 and $30 \mathrm{nA}$, respectively, for the pool size. This is a 2.1 and $2.5 \times$ larger pool size estimate for P12-P14 than for P5-P7. Because the $300 \mathrm{~Hz}$ train was presumably more depleting than $100 \mathrm{~Hz}$, we estimate that the average pool size at P12-P14 is probably closer to $30 \mathrm{nA}$. In fact, 


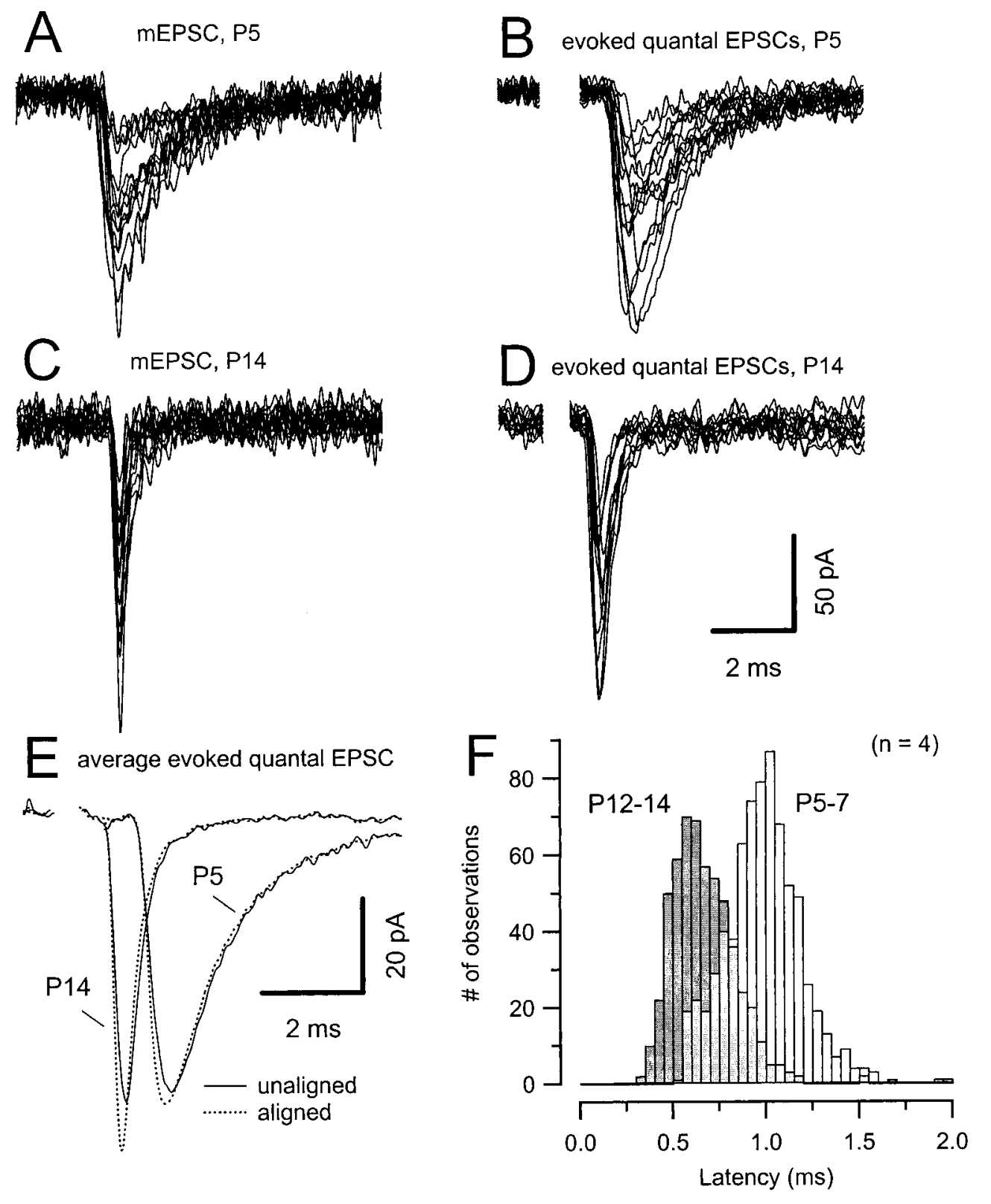

Figure 5. Asynchronous transmitter release does not account for slower EPSC waveforms in P5-P7 slices. A, C, Spontaneous miniature EPSCs recorded at $\mathrm{P} 5$ $(A)$ and P14 $(C)$ are superimposed and aligned at their peak amplitude. $B, D$, Evoked quantal EPSCs recorded at greatly reduced probability of release $(50$ $\mu \mathrm{M} \mathrm{CdCl}$ included in the bath solution) at P5 $(B)$ and P14 $(D)$. Occasionally occurring EPSCs with amplitudes $>150 \mathrm{pA}$ were discarded. The events in $A-D$ are from four different cells, and 15 sample traces are shown superimposed. mEPSCs were collected under the same recording

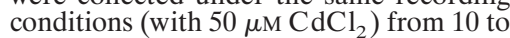
$200 \mathrm{msec}$ after the stimulus. Note the difference in synaptic delays and EPSC kinetics in $B$ and $D$. Stimulus frequency for evoked quantal events was 1-2 Hz. E, Average waveforms of quantal EPSCs were obtained either with (dotted lines) or without (solid lines) previous aligning of individual EPSCs at their $50 \%$ rise points. 170 and 125 responses were averaged for P5 and P14, respectively. At both ages, aligned EPSC gave rise to slightly faster kinetics of the averaged EPSC waveform. $20-80 \%$ rise times were 221 versus 310 $\mu \mathrm{sec}$ (P5) and 128 versus $176 \mu \mathrm{sec}$ (P14) for the aligned and unaligned EPSCs, respectively. Half widths were 1406 versus $1477 \mu$ sec (P5) and 441 versus $541 \mu \mathrm{sec}$ (P14) for waveforms obtained from aligned and unaligned EPSC, respectively. $F$, Latency distribution of quantal EPSC. Latency was calculated as the time difference between negative peak of the prepotential and $20 \%$ rise point of the EPSCs. Pooled data obtained from four different cells in each age group. for some P14 cells (e.g., the cell shown in Fig. $6 F$ ), the cumulative EPSC, or pool size, was $40 \mathrm{nA}$. Moreover, because this analysis does not take into account AMPA receptor saturation or desensitization, this number is only a lower bound (Wu and Borst, 1999). The pool size could in fact be larger, especially considering that desensitization may be more pronounced at higher frequencies (Trussell, 1999). We thus conclude that the readily releasable pool size probably increased on average by a factor of at least 2.5 -fold from P5-7 to P12-P14.

\section{Effects of temperature on single EPSCs and EPSC trains}

We next studied the effects of temperature on EPSC kinetics and synaptic depression. High temperature had striking effects on single EPSCs and EPSC trains. We first noticed a marked decrease in the synaptic delay as temperature was increased from RT $\left(21-23^{\circ} \mathrm{C}\right)$ to $35^{\circ} \mathrm{C}$ (Fig. $\left.8 A, B\right)$. In younger animals we observed a larger decrease in synaptic delay than in older ones. At P5-P7 the synaptic delay decrease by $495 \pm 33 \mu$ sec $(n=7)$, whereas at P12-P14 the reduction was only $244 \pm 48 \mu \mathrm{sec}(n=$ $6)$. This difference was statistically significant ( $t$ test; $p<0.001$ ). Figure $8 C$ shows an expanded view of the prepotential and initial rise of the EPSC for a P6 cell. Previous observations in P8-P10 rats indicated a decrease in delay of $500 \mu \mathrm{sec}$ (Borst et al., 1995).
EPSC peak amplitudes also clearly increased at higher temperature, and both rise time and decay were faster (Fig. $8 A, B$; Zhang and Trussell, 1994b). Finally, the amplitude of the steady state depressed EPSC in a train was also increased by raising the temperature from $\mathrm{RT}$ to $35^{\circ} \mathrm{C}$ (Fig. $8 D$; Brenowitz et al., 1998). These effects will all clearly aid the synapse in its capacity to transmit at higher frequencies.

\section{DISCUSSION}

Our results indicate that the calyx of Held synapse undergoes major presynaptic and postsynaptic developmental changes that progressively lead to its capacity to follow near kilohertz frequencies of stimulation by the end of the second postnatal week.

\section{Presynaptic developmental changes}

Presynaptic APs were $>60 \%$ more brief for P12-P14 rats compared with P5-P7. Our P5-P7 calyx APs had amplitudes and half-widths similar to those reported previously for P8-P10 (Borst et al., 1995; Schneggenburger et al., 1999). However, the small afterhyperpolarization described for some P8-P10 APs (Borst et al., 1995), which was also present in our recordings from P12-P14 calyxes, was not seen at P5-P7. Interestingly, the calyx of Held 

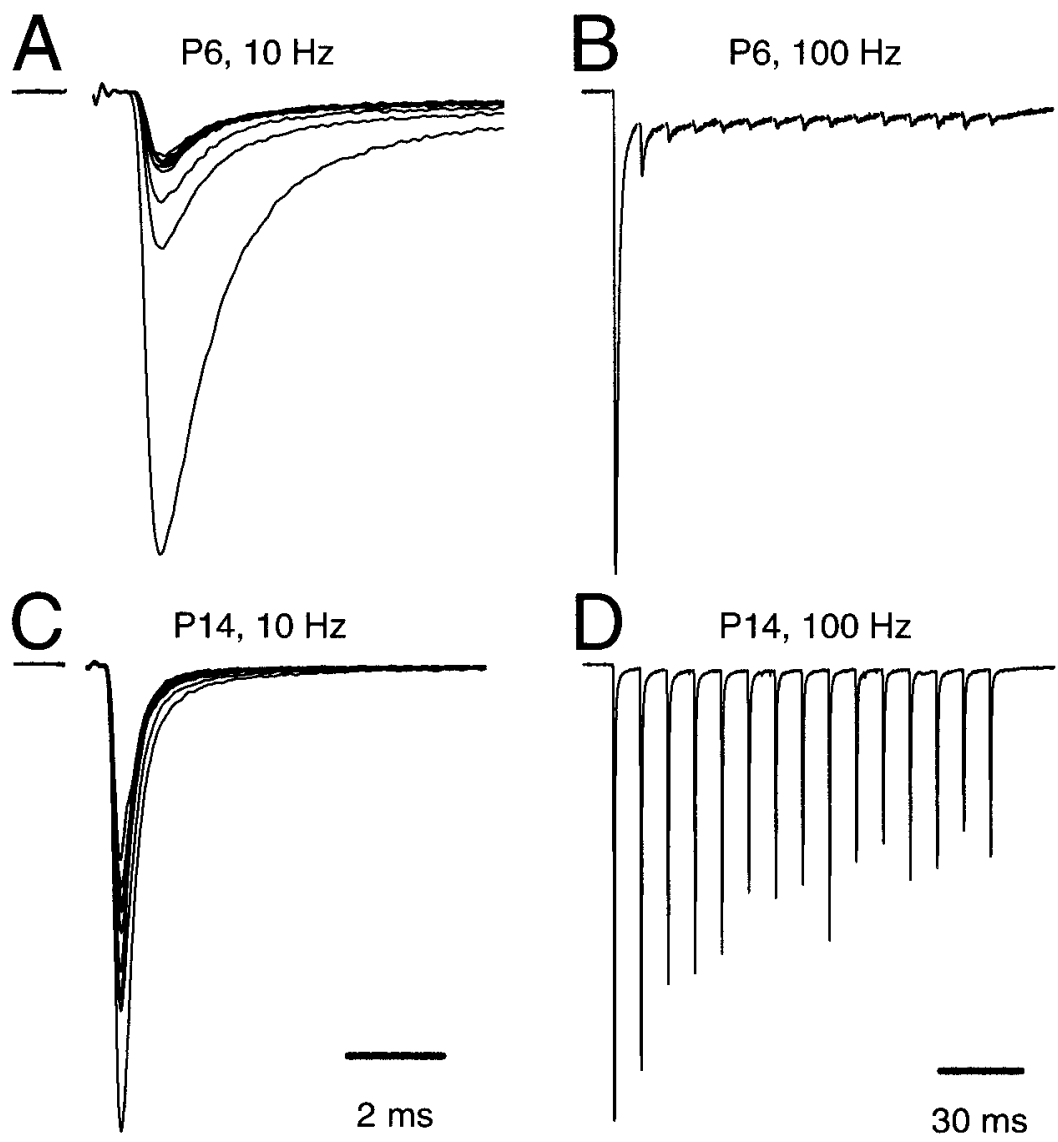

Figure 6. Frequency-dependent short-term depression at the calyx of Held synapse during development. $A-D$, EPSC trains evoked by afferent stimulation at $10 \mathrm{~Hz}(25$ stimuli; $A, C)$ and $100 \mathrm{~Hz}(15$ stimuli; $B, D)$. Data from two different cells $A, B$, P6; $C, D$, P14) with similar peak amplitudes of the initial EPSCs are shown. $V_{\mathrm{h}}=-70 \mathrm{mV} . E, F$, Same neuron as depicted in $C$ and $D$. Stimulation frequency was $300 \mathrm{~Hz}(E)$ and $500 \mathrm{~Hz}(F)$. For $A-F$, mean amplitudes of depressed EPSCs (last five EPSCs during a train) amounted to $1.91 \mathrm{nA}$ $(10 \mathrm{~Hz}), 0.32 \mathrm{nA}(100 \mathrm{~Hz})$, and $6.45 \mathrm{nA}(10 \mathrm{~Hz}), 5.41 \mathrm{nA}(100$ $\mathrm{Hz}), 2.98 \mathrm{nA}(300 \mathrm{~Hz})$, and $1.95 \mathrm{nA}(500 \mathrm{~Hz})$ for $\mathrm{P} 6$ and P14, respectively.

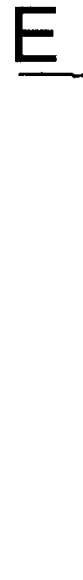

$\mathrm{P} 14,300 \mathrm{~Hz}$

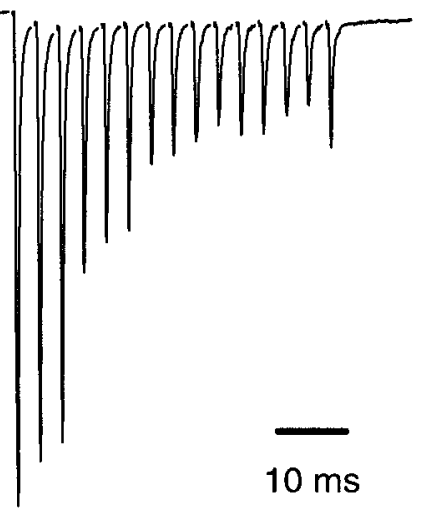

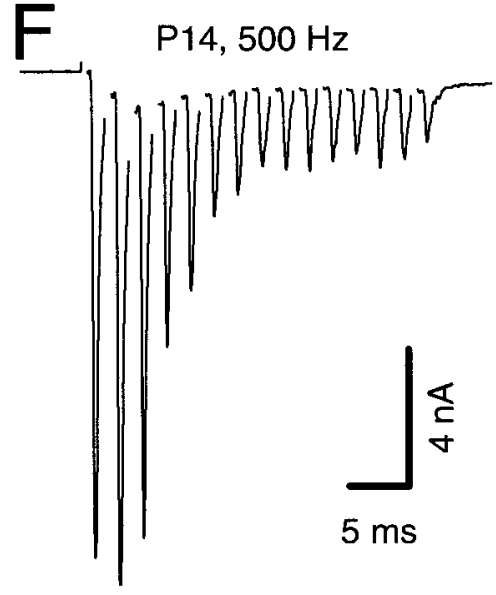

undergoes a dramatic morphological transition from a spoon-like, amoebae-shaped structure with fine appendages to a digitiform, floral-like structure during this period (Kandler and Friauf, 1993). Changes in presynaptic activity may further influence neuronal morphology (Pasic et al., 1994). Our results suggest that ion channel densities, kinetics, and/or repertoire (Tan and Llano, 1999) also change in parallel, leading to a briefer AP. We speculate that the faster AP kinetics may be caused by a higher density of $\mathrm{Na}^{+}$and $\mathrm{K}^{+}$channels with age (Wang et al., 1998).

Mechanisms for reducing synaptic delay and depression

A corollary effect of a shorter calyx AP is a briefer presynaptic $\mathrm{Ca}$ current. This will have important consequences. First, the earlier down stroke of the AP will trigger an earlier $\mathrm{Ca}$ current and thus shorten synaptic delay (Llinás, 1999). Interestingly, the average synaptic delay was reduced by $291 \mu$ sec from P5-P7 to P12-P14, whereas the average reduction in presynaptic AP half-width was $373 \mu \mathrm{sec}$ (see also Wu and Oertel, 1987). Thus, a large part of the reduction in synaptic delay may be related to the decrease in AP width with age. Second, the faster up and down stroke of the AP will open and close presynaptic $\mathrm{Ca}$ channels more quickly producing a more phasic and confined period of transmitter release. Indeed, we observed however only a slight sharpening of the quantal EPSC latency histogram (Fig. $5 F$ ). Finally, the briefer $\mathrm{Ca}$ current may reduce the probability of release. Accordingly, broader presynaptic APs are usually associated with larger EPSCs (Augustine, 1990; Wheeler et al., 1996; Wang and Kaczmarek, 1998; Borst and Sakmann, 1999). However, we did not observe a decrease in the initial EPSC amplitude with age. On the other hand, we did observed a decrease in the amount of paired-pulse depression when calculated from the first two EPSCs during a $10 \mathrm{~Hz}$ stimulus train (Fig. 6A,C), which again suggests a reduction in release probability (Stevens and Wang, 1995). The similar EPSC amplitudes in both age groups may thus be because of antagonistic effects of a decrease in release probability and an increase in vesicle pool size. The shortening of presynaptic APs may represent a possible general mechanism underlying the decrease in release probability typically 


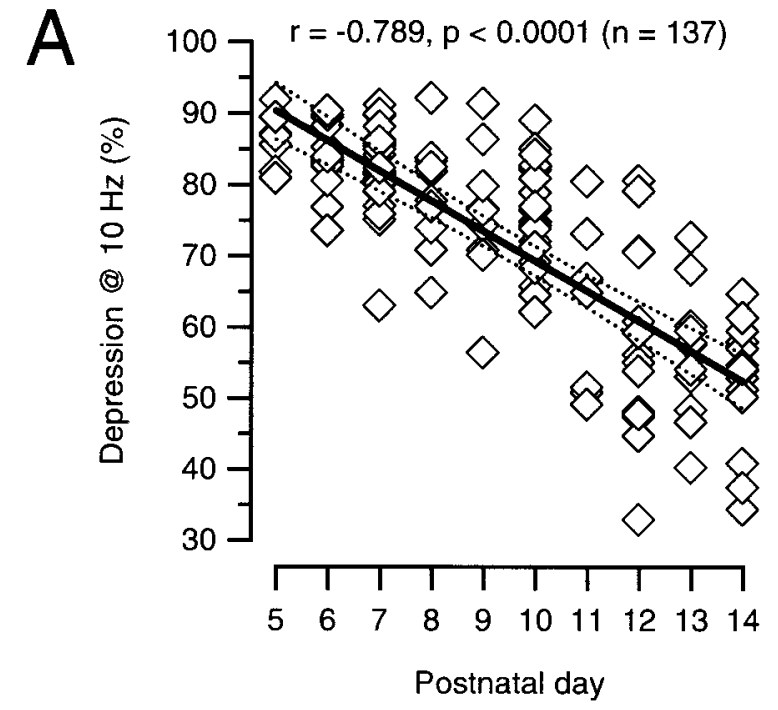

B

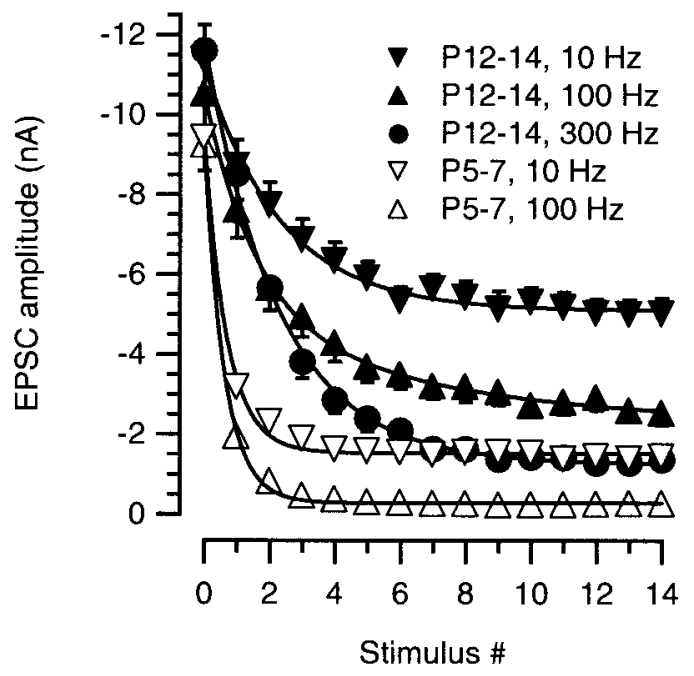

$\mathrm{C}$

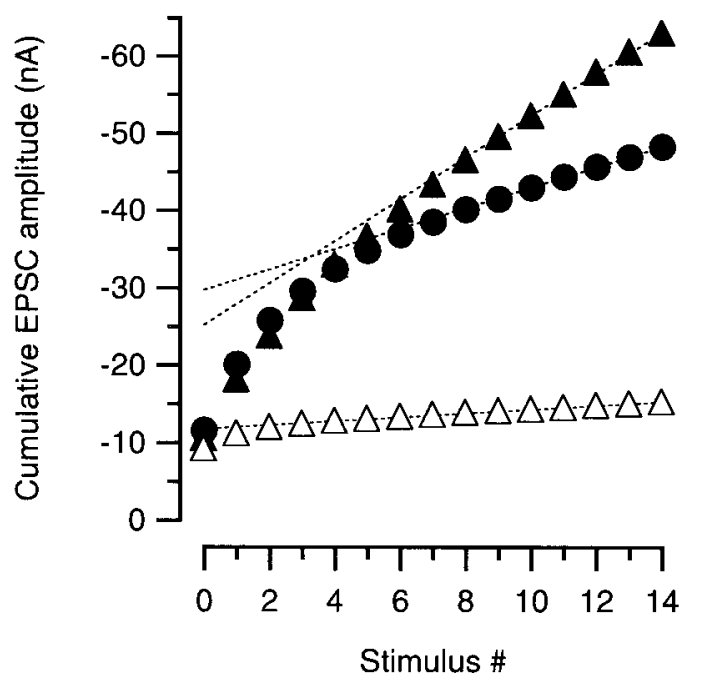

Figure 7. Synaptic depression and vesicle pool size during postnatal development. $A$, Synaptic depression at $10 \mathrm{~Hz}$. The ratio between the initial EPSC over the mean steady-state depressed EPSC (last five stimuli) after 25 stimuli was calculated for each cell and expressed as a percentage. Pooled data for a total of 115 cells plotted versus postnatal age. Solid and dotted lines indicate linear regression and $99 \%$ confidence limits, respectively. $B$, Average data of synaptic depression for various stimulation frequencies in P5-P7 (open symbols) and P12-P14 (filled symbols) slices. Three frequencies $(10,100$, and $300 \mathrm{~Hz} ; n=25$ cells) were tested for each age group. For P5-P7, depression obtained with 100 and $300 \mathrm{~Hz}$ was similar, and therefore observed at different CNS synapses during development (Bolshakov and Siegelbaum, 1995; Pouzat and Hestrin, 1997).

Another factor that consistently reduces synaptic delays is increasing temperature, which also leads to shorter presynaptic APs (Sabatini and Regehr, 1996; Llinás, 1999). Indeed, at $36^{\circ} \mathrm{C}$ the calyx AP half-width is only $250 \mu$ sec for P8-P10 rats (Borst and Sakmann, 1998). At mammalian physiological temperatures the adult calyx AP could last for only $100 \mu \mathrm{sec}$, and would thus be well suited for high-frequency transmission. The small variability in synaptic delays throughout development may be related to the calyceal geometry of the terminal that allows the invading AP to synchronously open a large number of $\mathrm{Ca}$ channels in spatially separated active zones. Interestingly, the mean synaptic delay of evoked quantal responses in the presence of $50 \mu \mathrm{M} C \mathrm{Cd}$ was increased by $\sim 180 \mu$ sec compared with the synaptic delay of the control EPSC (Table 1). This could be because of the greatly reduced presynaptic $\mathrm{Ca}$ current amplitude with $\mathrm{Cd}$.

It has previously been suggested for this synapse that synaptic depression induced at frequencies of $10-100 \mathrm{~Hz}$ is mainly caused by a reduction in glutamate release rather than postsynaptic receptor desensitization (von Gersdorff et al., 1997; Wang and Kaczmarek, 1998). Here we greatly extended the range of stimulation frequencies and found a remarkable reduction in the degree of depression during development. Presumably, young calyxes quickly exhaust their pool of readily releasable vesicles and are not able to replenish it fast enough. In fact, even at $10 \mathrm{~Hz}$ P5-P7 synapses undergo severe depression. On the other hand, much higher stimulation frequencies $(300-500 \mathrm{~Hz})$ were necessary to observe a similar amount of depression at P14. At this age, the terminal may have a larger initial vesicle pool and/or a more efficient capacity to replenish the depleted pool (Wang and Kaczmarek, 1998). Disregarding desensitization and assuming that the quantal size does not change significantly with development, as suggested by Figure $5 C$ (Chuhma and Ohmori, 1998), we roughly estimated an at least 2.5 -fold increase in pool size (12-30 nA). With a mean quantal amplitude of 32 pA (Chuhma and Ohmori, 1998; Schneggenburger et al., 1999) this could correspond to an average increase in pool size from $\sim 375$ to 940 vesicles. For P8-PP10 calyxes the estimated pool size is proportional to $18 \mathrm{nA}$ ( $\sim 600$ vesicles; Schneggenburger et al., 1999). Thus, there may be a progressive increase in vesicle pool size as the active zones mature during development.

\section{Postsynaptic changes that aid in high-frequency transmission}

The faster EPSC kinetics at P12-P14 could have presynaptic origins, such as less jitter in glutamate release. This could be caused by a developmental increase in the $\mathrm{Ca}^{+2}$ channel density (Chuhma and Ohmori, 1998). Alternatively, postsynaptic mechanisms could account for more rapid EPSC kinetics if the underlying AMPA receptors acquired a faster kinetics with age. Here we report that the kinetics of evoked quantal responses was similar to control EPSCs throughout development. The faster EPSC waveform at P12-P14 thus probably has a mostly postsynaptic origin, perhaps stemming from the expression of different AMPA receptors during development (Lawrence and Trussell, 2000). Interestingly, a recent developmental study of AMPA receptor subtype expression in the rat MNTB has revealed an increase in GluRD expression after P8 (Caicedo and Eybalin, 1999). AMPA receptors composed of this

only the $100 \mathrm{~Hz}$ data points were included. Solid lines represent single exponential fits to the data points ( $\tau$ values for 10 and $100 \mathrm{~Hz}$ were 69.2 and $6.1 \mathrm{msec}$ for P5-P7 vs 233.3 and 23.2 msec for P12-P14, respectively). Note that a 30 times higher stimulation frequency was necessary to obtain a similar amount of depression in P12-P14 slices as seen with $10 \mathrm{~Hz}$ at P5-P7. $C$, Cumulative EPSC amplitudes obtained by adding EPSC amplitudes during the 100 and $300 \mathrm{~Hz}$ trains (same symbols as in $B$ ) to estimate change in vesicle pool sizes. Dotted lines represent linear fits to the last five EPSC amplitudes during the train back-extrapolated to 0 to estimate the cumulative EPSC amplitudes before steady-state depression. At P12-P14, the estimated pool size was $2.5-3 \times$ larger than P5-P7. 

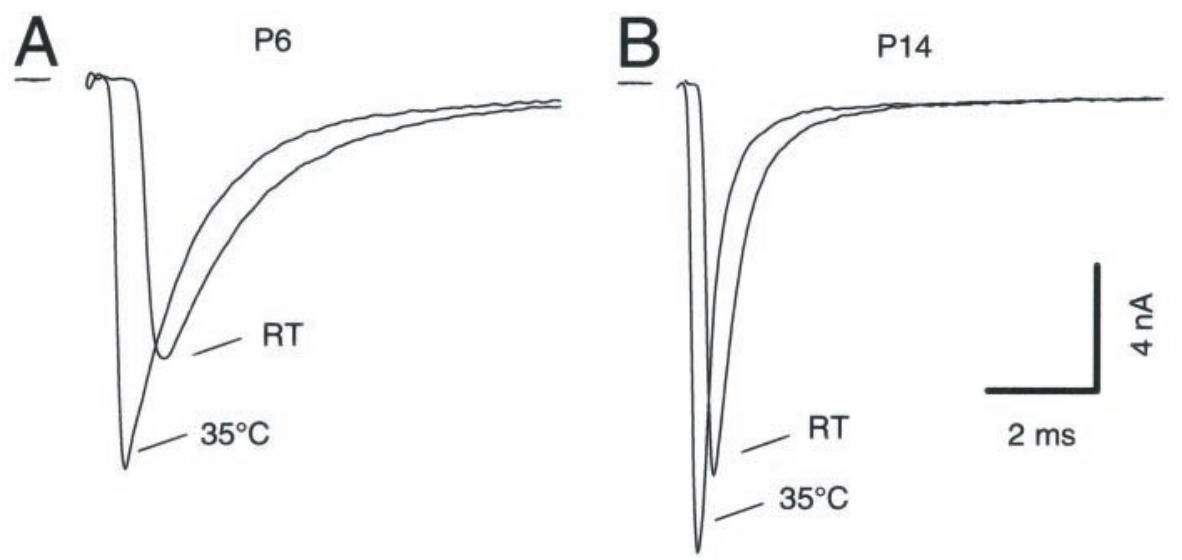

Figure 8. Temperature dependence of synaptic delay, EPSC time course, and synaptic depression. $A, B$, Comparison of EPSC waveforms at RT and $35^{\circ} \mathrm{C}$ for P6 $(A)$ and $\mathrm{P} 14(B)$ brainstem slices. The $20-80 \%$ rise times were 220 and $136 \mathrm{msec}(P 6)$ and 122 and $95 \mathrm{msec}$ (P14) for RT and $35^{\circ} \mathrm{C}$, respectively. $C$, Temperature-dependent shift of prepotential and EPSC onset in another P6 neuron shown at a faster time scale. $D$, Comparison of EPSCs evoked by high-frequency afferent stimulation $(100 \mathrm{~Hz})$ at room temperature (blue trace) and $35^{\circ} \mathrm{C}$ (red trace). Same neuron as shown in $B$. In this neuron, synaptic depression was reduced from $77 \%$ at room temperature to $65 \%$ at $35^{\circ} \mathrm{C}$. In these examples, the temperature was raised from RT $\left(21-23^{\circ} \mathrm{C}\right)$ to $35^{\circ} \mathrm{C}$ in $<5 \mathrm{~min}$, and all effects were fully reversible.
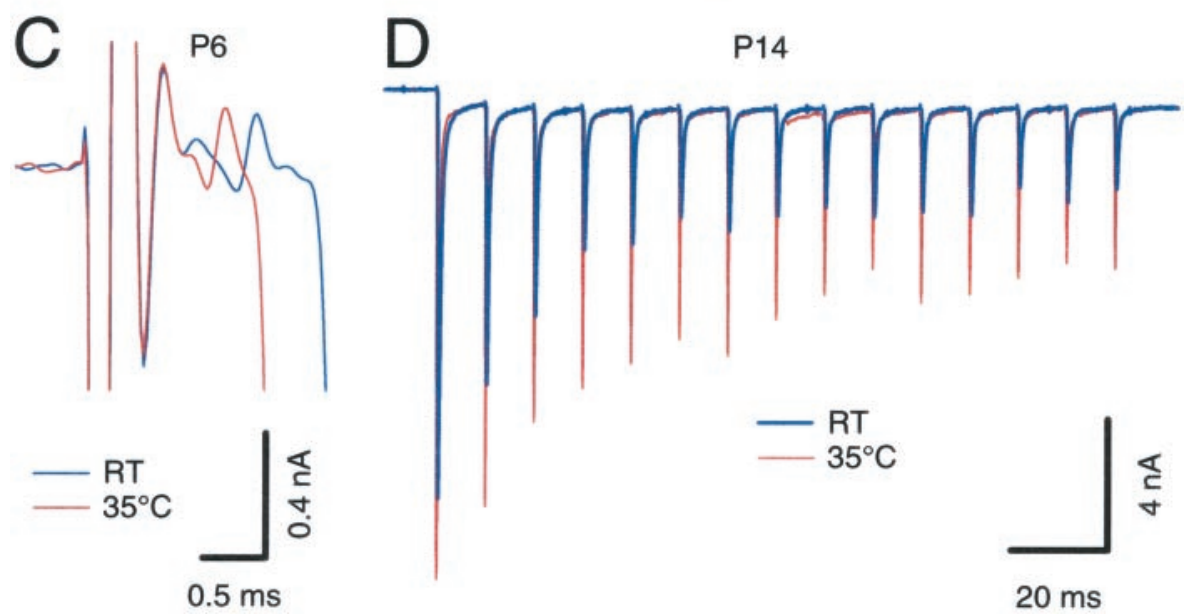

subunit have the fastest activation and deactivation kinetics (Geiger et al., 1995). We also emphasize that the average EPSC rise time of $127 \mu \mathrm{sec}$ measured for P12-P14 may have undergone significant filtering (Silver et al., 1992; Stiles et al., 1999). The unfiltered $20-80 \%$ rise time is likely to be $<100 \mu \mathrm{sec}$ in adult animals. Such fast rise times may be particularly suitable for registering the exact onset of stimuli.

In addition, we also observed a reduction in amplitudes and faster decays of NMDA EPSCs with development, as reported previously at other CNS synapses (Hestrin, 1992; Zhou and Parks, 1992; Shi et al., 1997). This may aid the synapse at high-frequency transmission by avoiding a large depolarizing plateau. Finally, we observed a progressive shortening of postsynaptic APs with age (Kandler and Friauf, 1995). Similarly, a shortening of somatic APs during development, because of an increase in delayed rectifier $\mathrm{K}^{+}$ channel density, was observed in developing Xenopus neurons (Spitzer and Ribera, 1998), which also undergo a developmental shift from NMDA to AMPA receptor expression (Wu et al., 1996).

\section{Comparison with previous studies and other synapses}

A previous study (Chuhma and Ohmori, 1998) of developmental changes in EPSCs at the calyx of Held focused on P4 to P11 rats and did not address changes in short-term plasticity during repetitive stimulation. We confirm their finding that postsynaptic APs jitter more in young rats, however we did not observe their large degree of EPSC asynchrony at P5-P7. Also, in contrast to this previous study, we observed a progressive decrease in EPSC rise times and no significant change in EPSC amplitudes from P5 to P14. In addition, we found significantly faster EPSC kinetics for mEPSC and evoked quantal responses at P12-P14. These differences may be attributable in part to the different ages used for comparisons and other methodological differences. Interestingly, at the end-bulb synapse of the rat cochlear nucleus, both EPSC quantal size and quantal content increased with age (Bellingham et al., 1998).

Reliable transmission occurred in P14 calyx of Held synapses at frequencies up to $800 \mathrm{~Hz}$. How does this compare to other synapses? In the neocortex, for example, synaptic depression can be already quite severe at $20-50 \mathrm{~Hz}$ (Galarreta and Hestrin, 1998; Varela et al., 1999). In the cochlear nucleus, however, octopus cells can follow inputs of up to $1000 \mathrm{~Hz}$, but accomplish this by receiving multiple synapses from distinct auditory nerve fibers (Rhode and Smith, 1986; Oertel, 1999). Thus, at a single synapse level, the calyx of Held synapse, with its multiple active zones, appears to be among the fastest and most reliable of CNS synapses in its ability to follow prolonged high-frequency input. As previously suspected from its unique morphology, the calyx of Held synapse thus seems specifically designed to operate at extreme speed, in a sustained manner, without succumbing to severe synaptic fatigue or depression.

\section{REFERENCES}

Augustine GJ (1990) Regulation of transmitter release at the squid giant synapse by presynaptic delayed rectifier potassium current. J Physiol (Lond) 431:343-364.

Banks MI, Smith PH (1992) Intracellular recordings from the neurobiotinlabeled cells in brain slices of the rat medial nucleus of the trapezoid body. J Neurosci 12:2819-2837.

Bellingham MC, Walmsley B (1999) A novel presynaptic inhibitory mechanism underlies paired pulse depression at a fast central synapse. Neuron 23:159-170.

Bellingham MC, Lim R, Walmsley B (1998) Developmental changes in EPSC quantal size and quantal content at a central glutamatergic synapse in rat. J Physiol (Lond) 511:861-869.

Blatchley BJ, Cooper WA, Coleman JR (1987) Development of auditory brainstem response to tone pip stimuli in the rat. Dev Brain Res 32:75-84.

Bolshakov VY, Siegelbaum SA (1995) Regulation of hippocampal transmitter release during development and long-term potentiation. Science 269:1730-1734.

Borst JGG, Sakmann B (1996) Calcium influx and transmitter release in a fast CNS synapse. Nature 383:431-434.

Borst JGG, Sakmann B (1998) Calcium current during a single action potential in a large presynaptic terminal of the rat brainstem. J Physiol (Lond) 506:143-157.

Borst JGG, Sakmann B (1999) Effect of changes in action potential shape 
on calcium currents and transmitter in a calyx-type synapse of the rat auditory brainstem. Phil. Trans. Roy. Soc. B354:347-355.

Borst JGG, Helmchen F, Sakmann B (1995) Pre- and postsynaptic wholecell recordings in the medial nucleus of the trapezoid body of the rat. J Physiol (Lond) 489:825-840.

Barrett EF, Stevens CF (1972) The kinetics of transmitter release at the frog neuromuscular junction. J Physiol (Lond) 227:691-708.

Brenowitz S, David J, Trussell LO (1998) Enhancement of synaptic efficacy by presynaptic GABA $_{B}$ receptors. Neuron 20:135-141.

Brew H, Forsythe ID (1995) Two voltage-dependent $\mathrm{K}^{+}$conductances with complementary functions in postsynaptic integration at a centra auditory synapse. J Neurosci 15:8011-8022.

Caicedo A, Eybalin M (1999) Glutamate receptor phenotypes in the auditory brainstem and mid-brain of the developing rat. Eur J Neurosci 11:51-74.

Chuhma N, Ohmori H (1998) Postnatal development of phase-locked high-fidelity synaptic transmission in the medial nucleus of the trapezoid body of the rat. J Neurosci 18:512-520.

Diamond JS, Jahr CE (1995) Asynchronous release of synaptic vesicles determines the time course of AMPA receptor-mediated EPSC. Neuron 15:1097-1107.

Elezgarai I, Benitez R, Mateos JM, Lázaro E, Osorio A, Azkue JJ, Bilbao A, Lingenhoehl K, van den Putten H, Hampson DR, Kuhn R, Knöpfel T, Grandes P (1999) Developmental expression of group III metabotropic glutamate receptor mGluR4a in the medial nucleus of the trapezoid body of the rat. J Comp Neurol 411:431-440.

Flint AC, Maisch US, Weishaupt JH, Kriegstein AR, Monyer H (1997) NR2A subunit expression shortens NMDA receptor synaptic currents in developing neocortex. J Neurosci 17:2469-2476.

Forsythe ID (1994) Direct patch recording from identified presynaptic terminals mediating glutamatergic EPSCs in the rat CNS, in vitro. J Physiol (Lond) 479:381-387.

Forsythe ID, Barnes-Davies M (1993) The binaural auditory pathway: excitatory amino acid receptors mediate dual time course excitatory postsynaptic currents in the rat medial nucleus of the trapezoid body. Proc R Soc Lond B Biol Sci 251:151-157.

Forsythe ID, Tsujimoto T, Barnes-Davies M, Cuttle MF, Takahashi T (1998) Inactivation of presynaptic calcium current contributes to synaptic depression at a fast central synapse. Neuron 20:797-807.

Friauf E (1992) Tonotopic order in the adult and developing auditory system of the rat as shown by c-fos immunocytochemistry. Eur J Neurosc 4:798-812.

Galarreta M, Hestrin S (1998) Frequency-dependent synaptic depression and the balance of excitation and inhibition in the neocortex. Nat Neurosci 1:587-594.

Geiger JRP, Melcher T, Koh D-S, Sakmann B, Seeburg PH, Jonas P, Monyer H (1995) Relative abundance of subunit mRNAs determines gating and $\mathrm{Ca}^{2+}$ permeability of AMPA receptors in principle neurons and interneurons in rat CNS. Neuron 15:193-204.

Guinan JJ, Li RY-S (1990) Signal processing in brainstem auditory neurons which receive giant endings (calyces of Held) in the medial nucleus of the trapezoid body of the cat. Hear Res 49:321-334.

Hestrin S (1992) Developmental regulation of NMDA receptor-mediated synaptic currents at a central synapse. Nature 357:686-689.

Isaacson JS, Walmsley B (1995) Counting quanta: direct measurements of transmitter release at a central synapse. Neuron 15:875-884.

Iwasaki S, Takahashi T (1998) Developmental changes in calcium channel types mediating synaptic transmission in rat auditory brainstem. J Physio (Lond) 509:419-423.

Kandler K, Friauf E (1993) Pre- and postnatal development of efferent connections of the cochlear nucleus in the rat. J Comp Neurol 328:161-184.

Kandler K, Friauf E (1995) Development of electrical membrane properties and discharge characteristics of superior olivary complex neurons in fetal and postnatal rats. Eur J Neurosci 7:1773-1790.

Katz B, Miledi R (1965) The measurement of synaptic delay, and the time course of acetylcholine release at the neuromuscular junction. Proc R Soc Lond B Biol Sci B161:483-495.

Lawrence JJ, Trussell LO (2000) Long-term specification of AMPA receptor properties after synapse formation. J Neurosci 20:4864-4870.

Llinás RR (1999) The squid giant synapse: a model for chemical transmission. New York: Oxford.

Lohmann C, Friauf E (1996) Distribution of the calcium-binding proteins parvalbumin and calretinin in the auditory brainstem of adult and developing rats. J Comp Neurol 367:90-109.

Oertel D (1983) Synaptic responses and electrical properties of cells in brain slices of the mouse anteroventral cochlear nucleus. J Neurosci 3:2043-2053.

Oertel D (1999) The role of timing in the brainstem auditory nuclei of vertebrates. Annu Rev Physiol 61:497-519.

Oliver D, Fakler B (1999) Expression density and functional characteristics of the outer hair cell motor protein are regulated during postnatal development in the rat. J Physiol (Lond) 519:791-800.

Park TJ, Monsivais P, Pollack GD (1997) Processing of internaural intensity differences in the LSO: role of interaural threshold differences. J Neurophysiol 77:2863-2878.

Pasic TR, Moore DR, Rubel EW (1994) Effect of altered neuronal activity on cell size in the medial nucleus of the trapezoid body and ventral cochlear nucleus of the gerbil. J Comp Neurol 348:111-120.
Pouzat C, Hestrin S (1997) Developmental regulation of basket/stellate cell $\rightarrow$ Purkinje cell synapses in cerebellum. J Neurosci 17:9104-9112.

Puel J-L, Uziel A (1987) Correlative development of cochlear action potential sensitivity, latency, and frequency selectivity. Dev Brain Res 32:179-188.

Reyes AD, Rubel EW, Spain WJ (1996) In vitro analysis of optimal stimuli for phase-locking and time-delayed modulation of firing in avian nucleus laminaris neurons. J Neurosci 16:993-1007.

Rhode WS, Smith PH (1986) Encoding timing and intensity in the ventral cochlear nucleus of the cat. J Neurophysiol 56:261-286.

Sabatini BL, Regehr WG (1996) Timing of neurotransmitter at fast synapses in the mammalian brain. Nature 384:170-172.

Sabatini BL, Regehr WG (1997) Control of neurotransmitter release by presynaptic waveform at the granule cell to Purkinje cell synapse. J Neurosci 17:3425-3435.

Sanes DH (1990) An in vitro analysis of the sound localization mechanism in the gerbil lateral superior olive. J Neurosci 10:3494-3506.

Schneggenburger R, Meyer AC, Neher E (1999) Released fraction and total size of a pool of immediately available transmitter quanta at a calyx synapse. Neuron 23:399-409.

Schwarz JR, Eikhof G (1987) Na currents and action potentials in rat myelinated nerve fibers at 20 and $37^{\circ} \mathrm{C}$. Pflügers Arch 409:560-577.

Shi J, Aamodt SM, Constantine-Paton M (1997) Temporal correlations between functional and molecular changes in NMDA receptors and GABA neurotransmission in the superior colliculus. J Neurosci 17:6264-6276.

Sigworth FJ, Affolter H, Neher E (1995) Design of a computer-controlled patch-clamp amplifier. II. Internal software. J Neurosci Methods 56:203-215.

Silver RA, Traynelis SF, Cull-Candy SG (1992) Rapid-time-course miniature and evoked excitatory currents at cerebellar synapses in situ. Nature 355:163-166.

Smith PH, Joris PX, Yin TCT (1998) Anatomy and physiology of principal cells of the medial nucleus of the trapezoid body (MNTB) of the cat. J Neurophysiol 79:3127-3142.

Spirou GA, Brownell WE, Zidanic M (1990) Recordings from cat trapezoid body and HRP labeling of globular bushy cell axons. J Neurophysiol 63:1169-1190.

Spitzer N, Ribera A (1998) Development of electrical excitability in embryonic neurons: mechanisms and roles. J Neurobiol 37:190-197.

Stiles JR, Kovyazina IV, Salpeter EE, Salpeter MM (1999) The temperature sensitivity of miniature currents is mostly by channel gating: evidence from optimized recordings and Monte Carlo simulations. Biophys J 77:1177-1187.

Stevens CF, Wang Y (1995) Facilitation and depression at single central synapses. Neuron 14:795-802.

Tan YP, Llano I (1999) Modulation by $\mathrm{K}^{+}$. channels of action potentialevoked intracellular $\mathrm{Ca}^{2+}$ concentration rises in rat cerebellar basket cell axons. J Physiol (Lond) 520:65-78.

Trussell LO (1999) Physiology of glutamatergic transmission at calyceal and endbulb synapses of the central auditory pathway. In: Handbook of experimental pharmacology, Vol 141 (Jonas P and Monyer H, eds), pp 399-418. Berlin: Springer.

Varela JA, Song S, Turrigiano GG, Nelson SB (1999) Differential depression at excitatory and inhibitory synapses in visual cortex. J Neurosci 19:4293-4304

von Gersdorff H, Schneggenburger R, Weis S, Neher E (1997) Presynaptic depression at a calyx synapse: The small contribution of metabotropic glutamate receptors. J Neurosci 17:8137-8146.

Wang L-Y, Kaczmarek LK (1998) High-frequency firing helps replenish the readily releasable pool of synaptic vesicles. Nature 394:384-388.

Wang L-Y, Gan L, Forsythe ID, Kaczmarek LK (1998) Contribution of the Kv3.1 potassium channel to high frequency firing in mouse auditory neurones. J Physiol (Lond) 509:183-194.

Wheeler DB, Randall A, Tsien RW (1996) Changes in action potential duration alter reliance of excitatory synaptic transmission on multiple types of $\mathrm{Ca}^{2+}$ channels in rat hippocampus. J Neurosci 16:2226-2237.

Wu G, Malinow R, Cline HT (1996) Maturation of a central glutamatergic synapse. Science 274:972-976.

Wu L-G, Borst JGG (1999) The reduced release probability of releasable vesicles during recovery from short-term synaptic depression. Neuron 23:821-832.

Wu SH, Oertel D (1987) Maturation of synapses and electrical properties of cells in the cochlear nuclei. Hear Res 30:99-110.

Wu SH, Kelly JB (1993) Response of neurones in the lateral superior olive and medial nucleus of the trapezoid body to repetitive stimulation: intracellular and extracellular recordings from the mouse brain slice. Hear Res 68:189-201.

Zhang S, Trussell LO (1994a) A characterization of excitatory postsynaptic potentials in the avian nucleus magnocellularis. J Neurophysiol 72:705-718.

Zhang S, Trussell LO (1994b) Voltage clamp analysis of excitatory synaptic transmission in the avian nucleus magnocellularis. J Physiol (Lond) 480:123-136.

Zhou N, Parks TN (1992) Developmental changes in the effects of drugs acting at NMDA or non-NMDA receptors on synaptic transmission in the chick cochlear nucleus (nuc. Magnocellularis). Dev Brain Res 67: $145-152$. 